\title{
Calcineurin inhibitors suppress acute graft-versus-host disease via NFAT-independent inhibition of T cell receptor signaling
}

\author{
Shizuka Otsuka, ${ }^{1}$ Nicolas Melis, ${ }^{2}$ Matthias M. Gaida, ${ }^{3}$ Debjani Dutta, ${ }^{1}$ Roberto Weigert, ${ }^{2}$ and Jonathan D. Ashwell ${ }^{1}$ \\ 'Laboratory of Immune Cell Biology and '2Laboratory of Cellular and Molecular Biology, National Cancer Institute, National Institutes of Health, Bethesda, Maryland, USA. Innstitute of Pathology, University \\ Medical Center Mainz, Mainz, Germany.
}

\begin{abstract}
Inhibitors of calcineurin phosphatase activity (CNIs) such as cyclosporin A (CsA) are widely used to treat tissue transplant rejection and acute graft-versus-host disease (aGVHD), for which inhibition of gene expression dependent on nuclear factor of activated T cells (NFAT) is the mechanistic paradigm. We recently reported that CNIs inhibit TCR-proximal signaling by preventing calcineurin-mediated dephosphorylation of $\mathrm{Lck}^{559}$, an inhibitory modification, raising the possibility of another mechanism by which CNIs suppress immune responses. Here we used T cells from mice that express Lck ${ }^{559 A}$, which cannot accept a phosphate at residue 59, to initiate aGVHD. Although CsA inhibited NFAT-dependent gene upregulation in alloaggressive $T$ cells expressing either $L_{c k}{ }^{W T}$ or $L_{c k}{ }^{559 A}$, it was ineffective in treating disease when the T cells expressed Lck ${ }^{559 A}$. Two important NFAT-independent T cell functions were found to be CsA-resistant in Lck ${ }^{559 \mathrm{~A}} \mathrm{~T}$ cells: upregulation of the cytolytic protein perforin in tissue-infiltrating CD8+ $T$ cells and antigen-specific T/DC adhesion and clustering in lymph nodes. These results demonstrate that effective treatment of aGVHD by CsA requires NFAT-independent inhibition of TCR signaling. Given that NFATs are widely expressed and off-target effects are a major limitation in CNI use, it is possible that targeting TCR-associated calcineurin directly may provide effective therapies with less toxicity.
\end{abstract}

\section{Introduction}

The suppression of immune responses is one of the pillars of therapeutic strategies to treat autoimmunity, immune-mediated inflammatory diseases, and rejection of transplanted tissue (1-3). Activated $\mathrm{T}$ cells play a central pathological role in these situations by a variety of mechanisms, including the production of proinflammatory cytokines, expression of death receptor ligands, and anti-self-cytotoxicity. The major classes of immunosuppressive drugs include glucocorticoids, mTOR inhibitors, antiproliferative compounds, and calcineurin inhibitors (CNIs) (4). The last group is composed of cyclosporin A (CsA) and FK506 (Tacrolimus), therapeutic mainstays that have been used for more than 30 years (5). Whereas the first 3 classes have wide-ranging effects on many cell types, the efficiency of CNIs is thought to be primarily via their effect on the expansion and function of $\mathrm{T}$ cells, in particular by inhibiting the production of IL-2 as well as effector cytokines such as TNF- $\alpha$, INF- $\gamma$, and others (6-8).

$\mathrm{T}$ cells are activated when their T cell antigen receptor (TCR) encounters its cognate antigen presented by MHC-encoded molecules on antigen-presenting cells (APCs). Upon productive TCR

Related Commentary: https://doi.org/10.1172/JCl149934

Conflict of interest: The authors have declared that no conflict of interest exists. Copyright: @ 2021, American Society for Clinical Investigation.

Submitted: January 12, 2021; Accepted: March 31, 2021; Published: June 1, 2021.

Reference information: J Clin Invest. 2021;131(11):e147683.

https://doi.org/10.1172/JCl147683. engagement the Src family tyrosine kinase Lck is recruited to the ligand-bound TCR and initiates a cascade of phosphorylation events that include tyrosine phosphorylation of PLC $\gamma 1$. Activated PLC 11 hydrolyzes phosphatidylinositol 4,5-bisphosphate (PIP2) to yield inositol 1,4,5-triphosphate (IP3), which binds its receptor on the endoplasmic reticulum, leading to the opening of $\mathrm{Ca}^{2+}$ channels and an increase in cytosolic $\mathrm{Ca}^{2+}$. The resulting rise in intracellular calcium levels triggers the activation of $\mathrm{Ca}^{2+} /$ calmodulindependent (CaM-dependent) phosphatase calcineurin. Elevated cytosolic $\mathrm{Ca}^{2+}$ leads to the occupancy of all calcium-binding sites in $\mathrm{CaM}$, which undergoes a significant conformational change and binds to and activates calcineurin. The major target of activated calcineurin is the nuclear factor of activated T cells (NFAT) family of transcription factors. NFATs are constitutively phosphorylated on many serine/threonine residues, which causes them to reside in the cytoplasm. When dephosphorylated by $\mathrm{Ca}^{2+} /$ calmodulinactivated calcineurin, nuclear localization sequences are exposed and NFATs translocate to the nucleus and upregulate the expression of target genes, which include many important cytokines such as IL-2, IFN- $\gamma$, and TNF- $\alpha$, as well as cell surface molecules such as CD40L, CD95, and CD25 (IL-2R $\alpha$ ), which are necessary for regulation of $\mathrm{T}$ cell-mediated immune responses (9).

CNIs target calcineurin indirectly by forming complexes with cytosolic proteins known as immunophilins: CsA-cyclophilin A and FK506-FKBP12. The complexes bind calcineurin and prevent interaction with $\mathrm{Ca}^{2+} /$ calmodulin, resulting in decreased catalytic activity $(8,10)$. It is generally accepted that CNIs prevent $\mathrm{T}$ cell proliferation and proinflammatory cytokine production by inhibit- 


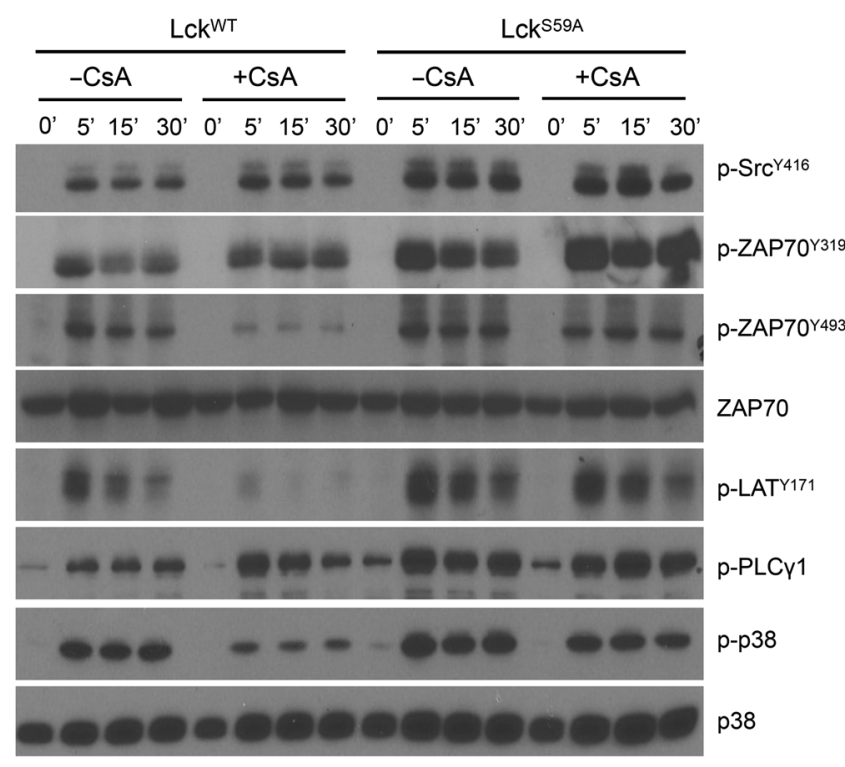

ing the calcineurin-NFAT pathway and thus NFAT-dependent gene expression (11). However, another possible target has emerged from the recent finding that calcineurin has a second major function in $\mathrm{T}$ cells - promoting early TCR-initiated signaling pathways (12). Calcineurin is rapidly recruited to the TCR signaling complex where it dephosphorylates $\mathrm{Lck}^{\mathrm{S59}}$, a site that is phosphorylated as the result of a negative feedback loop possibly involving ERKs $(12,13)$. Treatment with CsA or FK506 resulted in an increase in phospho-Lck ${ }^{559}$ and diminished phosphorylation of important signaling intermediates such as ZAP-70 ${ }^{\mathrm{Y} 493}$, LAT $^{\mathrm{Y} 171}$, and SLP-76. Experiments with transfected Jurkat $\mathrm{T}$ leukemic cells expressing Lck $^{\mathrm{S} 59 \mathrm{~A}}$ (which cannot accept a phosphate at residue 59) found increased phosphorylation and activation of signaling molecules such as $\mathrm{Lck}^{\mathrm{Y} 394}$, $\mathrm{ZAP7O}^{\mathrm{Y} 493}$, ZAP70 ${ }^{\mathrm{Y} 319}$, and $\mathrm{p} 38^{\mathrm{T} 180 / \mathrm{Y} 182}$, confirming that phosphorylation of $\mathrm{Lck}^{\mathrm{S59}}$ is an inhibitory modification (12). Importantly, CsA was shown to inhibit activation-induced LFA-1-ICAM1-dependent $\mathrm{T}$ cell/APC adhesion, a necessary step in $\mathrm{T}$ priming and activation. This adhesion, which occurs within minutes of activation, was independent of NFAT-mediated gene transcription. Moreover, Jurkat $\mathrm{T}$ cells expressing $\mathrm{Lck}^{\mathrm{S59A}}$ were resistant to CsA (12), which identified proximal TCR signaling and upregulation of LFA-1 affinity as a new target for CNIs. The findings raise the question of how CNIs actually mediate clinical immunosuppression. Is it by the present paradigm (inhibition of NFAT-dependent gene transcription), inhibition of $\mathrm{Lck}^{559}$ dephosphorylation, or a combination of the two? Here we addressed this by comparing the therapeutic efficacy of CsA for acute graft-vs-host disease (aGVHD), in which the pathology is largely due to inflammatory mediators and perforin/granzyme B or Fas/FasL-mediated cytotoxicity, in mice expressing WT Lck or Lck ${ }^{559 A}$. Although treatment with CsA reduced expression of the NFAT-dependent genes IL-2 and IFN- $\gamma$ to the same degree in T cells of both genotypes, $\mathrm{Lck}^{\mathrm{S} 59 \mathrm{~A}}$ responded much less well to the therapeutic effect of CsA than WT mice, which correlated with increased $\mathrm{T}$ cell infiltration in target organs and greater immunopathology as well as failure to inhibit several important $\mathrm{T}$ cell effector functions. Thus, the therapeutic effect of CsA in aGVHD requires its inhibition of $\mathrm{Lck}^{\mathrm{S59}}$ dephosphorylation by calcineurin.
Figure 1. T cells expressing Lck ${ }^{559 A}$ are insensitive to CsA effects on TCR proximal signaling. WT and $\mathrm{Lck}^{559 \mathrm{~A}} \mathrm{~T}$ cells were stimulated with soluble anti-CD3 and crosslinked with anti-hamster IgC at $37^{\circ} \mathrm{C}$ at the indicated times in the presence or absence of $\operatorname{CsA}(100 \mathrm{ng} / \mathrm{mL})$. Cell lysates were immunoblotted with phosphorylated $\mathrm{Src}^{\mathrm{Y} 416}, \mathrm{ZAP7O}^{\mathrm{\gamma 493}}, \mathrm{ZAP}^{\mathrm{Y} 319}, \mathrm{LAT}^{\mathrm{V} 171}$, $P L C \gamma 1^{1783}, p 38^{T 180 / 1182}, Z A P 70$, and $p 38$. Data are representative of 3 independent experiments.

\section{Results}

Characterization of $L c k^{559 A}$-expressing primary $T$ cells. We previously reported that calcineurin enzymatic activity was required for the normal propagation of signals initiated by TCR ligation, and used human Jurkat leukemia cells expressing mutated forms of Lck to identify dephosphorylation of Ser $59\left(\mathrm{Lck}^{\mathrm{S5}}\right)$ as the mechanism (12). To study the consequences of calcineurin inhibition in physiologic settings, we obtained knock-in mice in which Ser 59 has been replaced with Ala, precluding phosphorylation at this site $\left(\mathrm{Lck}^{559 \mathrm{~A}}\right)$. These mice are healthy, have a normal distribution and number of $\alpha \beta$ thymocytes and mature $\mathrm{T}$ cells, and have normal expression of activation and memory markers (14). To investigate proximal TCR signaling, T cells purified from lymph nodes were activated by crosslinking of antibodies to CD3. This results in the phosphorylation of $\mathrm{Lck}^{\mathrm{Y} 394}$ and a subsequent cascade of tyrosine phosphorylation events leading to initiation of $\mathrm{T}$ cell functions. As shown in Figure 1, TCR crosslinking of WT T cells resulted in rapid phosphorylation of $\mathrm{Lck}^{\mathrm{Y} 394}$ (detected by a cross-reactive antibody against murine $\left.\mathrm{Src}^{\mathrm{Y} 416}\right), \mathrm{ZAP} 0^{\mathrm{Y} 493}, \mathrm{ZAP}^{\mathrm{Y} 319}{ }^{\mathrm{Y}} \mathrm{LAT}^{\mathrm{Y} 171}, \mathrm{PLC} 1^{\mathrm{Y} 783}$, and $\mathrm{p} 38^{\mathrm{T} 180 / \mathrm{Y} 182}$. As observed with Jurkat cells expressing Lck $^{559 \mathrm{~A}}$ (12), these signaling

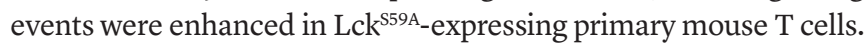
Phosphorylation of a subset of these events, ZAP70 ${ }^{\mathrm{Y} 493}$, LAT ${ }^{\mathrm{Y} 171}$, and $\mathrm{p} 38^{\mathrm{T} 180 / \mathrm{Y} 182}$, was shown to be inhibited by CsA. Notably, whereas CsA reduced phosphorylation of these signaling molecules in WT $\mathrm{T}$ cells, Lck ${ }^{55 \mathrm{~A}} \mathrm{~T}$ cells were insensitive (Figure 1). Thus, just as in Jurkat $\mathrm{T}$ leukemia cells, calcineurin-mediated dephosphorylation of $\mathrm{Lck}^{\mathrm{S59}}$ occurs early in the primary T cell activation pathway.

NFAT activation is normal and CsA-sensitive in $\mathrm{Lck}^{\mathrm{S} 59 \mathrm{~A}} \mathrm{~T}$ cells. To unambiguously interpret functional results obtained with $\mathrm{Lck}^{\mathrm{559A}} \mathrm{T}$ cells, one must be certain that this mutation does not affect activation of the best-characterized target of calcineurin, NFAT. NFAT1 is constitutively expressed in T cells and, once dephosphorylated by calcineurin, translocates into the nucleus and regulates transcription of target genes $(15,16)$. This was assessed in primary $\mathrm{T}$ cells using imaging flow cytometry, in which the intracellular localization of proteins of interest can be detected at a single cell level. Purified T cells from WT and $L c k^{559 A}$ mice were stimulated with anti-CD3, and NFAT1 distribution was imaged at 30 minutes. At 30 minutes, NFAT1 was found to be translocated to the nucleus in approximately $30 \%$ of $\mathrm{CD}^{+}{ }^{+} \mathrm{WT}$ and $\mathrm{Lck}^{\mathrm{S59A}} \mathrm{T}$ cells (Figure 2, A and B). This was, as expected, prevented by inhibiting calcineurin. The degree of NFAT1 translocation in Lck $^{\mathrm{S59A}} \mathrm{T}$ cells was similar to WT and was also blocked by CsA (Figure 2B). Similar results were obtained with WT and $\mathrm{Lck}^{\mathrm{S59A}} \mathrm{CD}^{+} \mathrm{T}$ cells (Figure $2 \mathrm{C}$ ). A perhaps more relevant way to assess the effect of calcineurin on NFAT is to quantitate the expression of NFAT-dependent gene products such as CD69 (17), CD25 (IL-2R $\alpha)(18)$, IL-2 (19, 20), and IFN- $\gamma$ (21, 22). CD69 and CD25, 2 early T cell activation markers, 
A
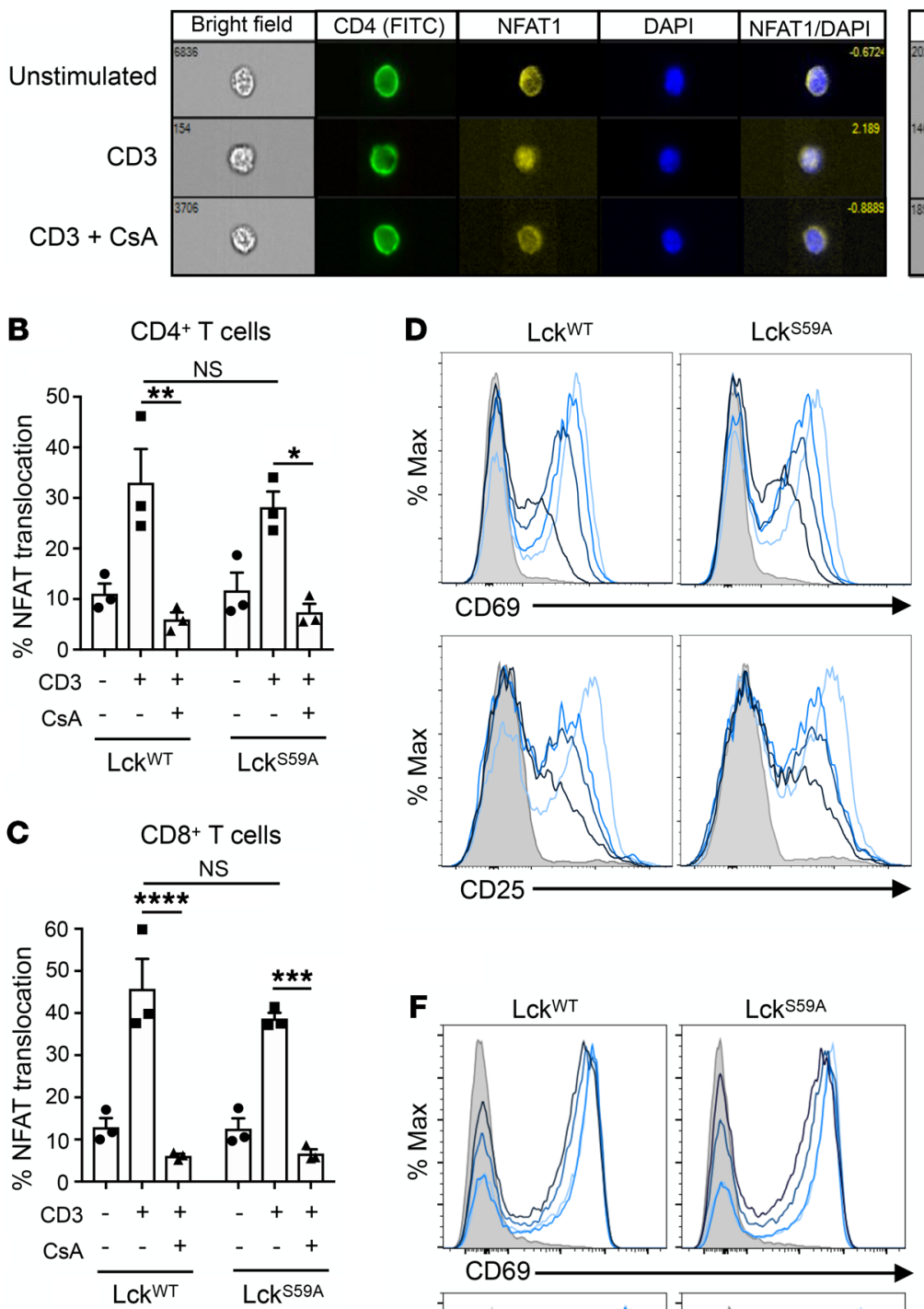

$\mathbf{F}$
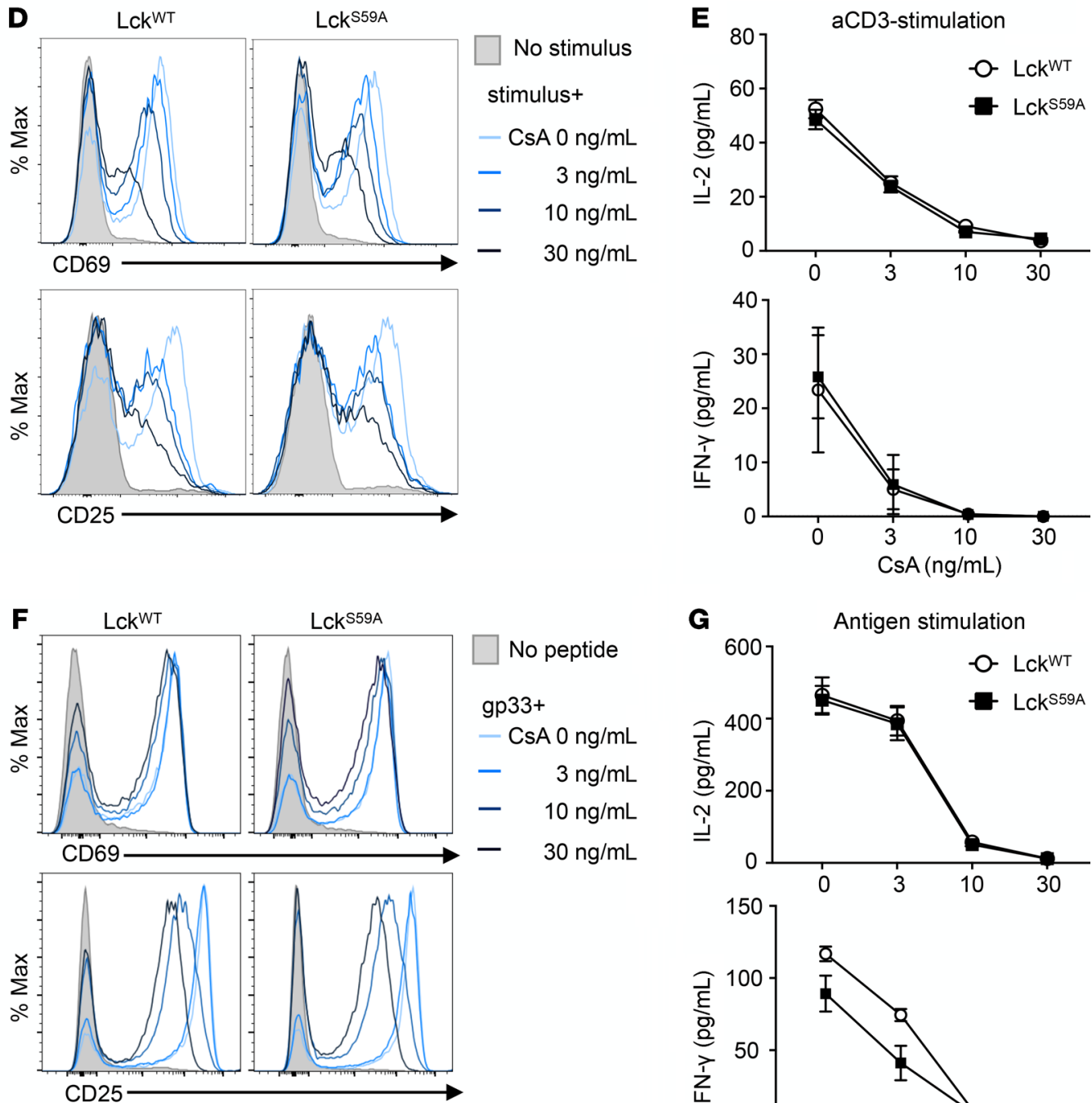

No peptide

G

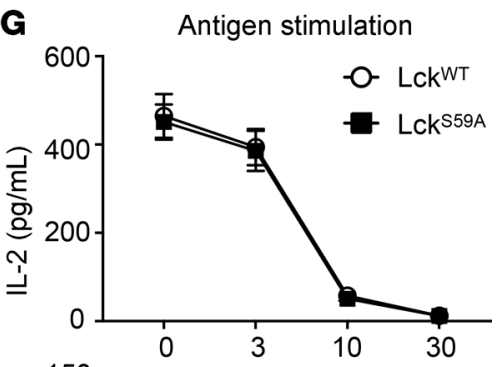

gp33+

- CsA $0 \mathrm{ng} / \mathrm{mL}$

- $\quad 3 \mathrm{ng} / \mathrm{mL}$

- $\quad 10 \mathrm{ng} / \mathrm{mL}$

- $\quad 30 \mathrm{ng} / \mathrm{mL}$

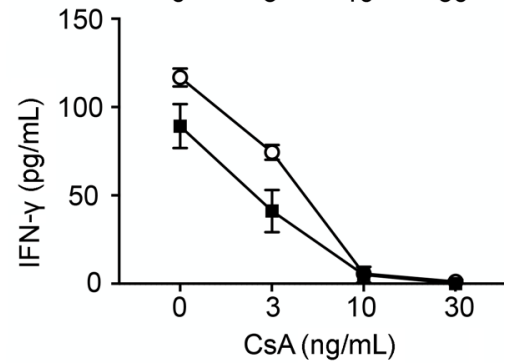

Figure 2. CsA inhibits NFAT activation in both WT and Lck ${ }^{559 A} \mathbf{T}$ cells. (A) Representative images of unstimulated, anti-CD3-stimulated, and anti-CD3 plus CsAstimulated WT and Lck ${ }^{559 A}$ CD4 ${ }^{+}$T cells stained with anti-CD4 (green), anti-NFAT1 (yellow), and DAPI (blue). (B and C) The percentage of cells with nuclear NFAT1 in $\mathrm{CD}^{+}$and CD8 ${ }^{+}$T cells. ${ }^{*} P<0.05$, ${ }^{* *} P<0.01$, ${ }^{* *} P<0.0001$, ${ }^{* * *} P<0.00001$ by 2 -way ANOVA with Tukey's multiple-comparison post hoc test. (D) CD69 and CD25 expression of anti-CD3/CD28-stimulated WT and Lck ${ }^{559 A}$ T cells with or without CsA for 6 hours analyzed by flow cytometry. (E) IL-2 and IFN- $\gamma$ secretion by antiCD3/CD28-stimulated WT and Lck ${ }^{559 A}$ T cells with or without CsA for 18 hours in the supernatant by ELISA. (F) CD69 and CD25 expression on P14-WT or P14-Lck ${ }^{559 A}$ T cells stimulated with gp33-pulsed DCs with or without CsA for 6 hours. (C) IL-2 and IFN- $\gamma$ secretion by P14-WT or P14-Lck ${ }^{559 A}$ T cells stimulated with gp33-pulsed DCs with or without CSA for 18 hours in the supernatant as measured by ELISA. The graphs show the mean \pm SEM of at least 3 independent experiments.

were equally upregulated upon stimulation in both WT Lck and Lck ${ }^{559 \mathrm{~A}} \mathrm{~T}$ cells. Consistent with NFAT1 nuclear translocation, in the presence of CsA both decreased in a CsA-dose dependent manner (Figure 2D). The production of IL-2 and IFN- $\gamma, 2$ crit- ical effector cytokines, was similarly inhibited by CsA in both WT and Lck ${ }^{559 \mathrm{~A}} \mathrm{~T}$ cells under stimulation with plate-coated antiCD3 (Figure 2E). To assess this in a more physiological context, we crossed $L c k^{559 A}$ mice with P14 mice, which express an $\alpha \beta$ TCR 
A CsA dose $(\mathrm{ng} / \mathrm{mL})$
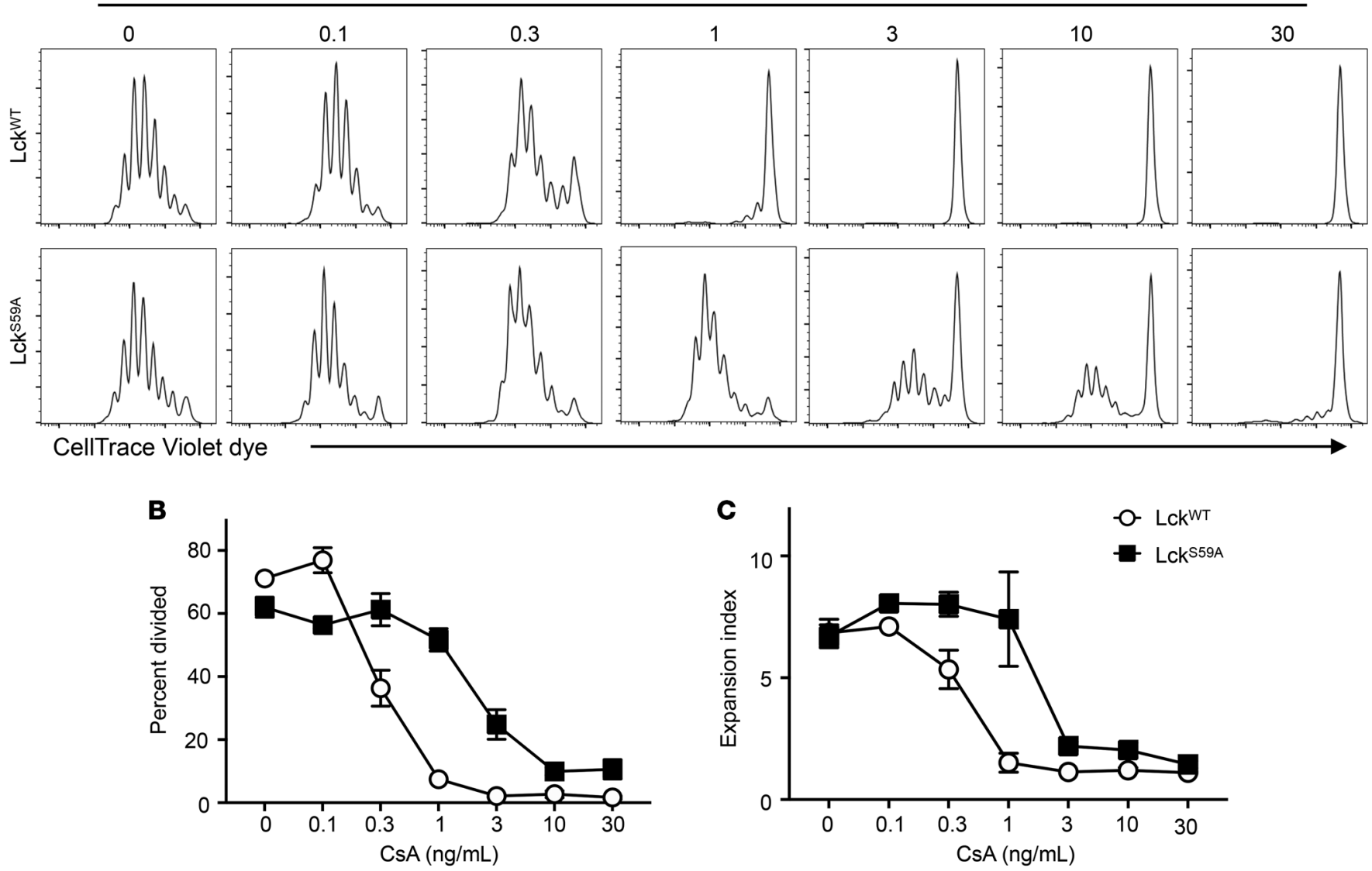

Figure 3. Inhibition of antigen-induced proliferation is more sensitive to CsA in WT than Lck ${ }^{559 A} \mathbf{T}$ cells. (A-C) Purified T cells were labeled with CellTrace Violet dye and stimulated with gp33-pulsed BMDCs for 48 hours. Samples were analyzed by flow cytometry. The percent division (B) and expansion index (C) were calculated by Flowjo software. The graphs show the mean \pm SD of 2 independent experiments.

specific for the lymphocytic choriomeningitis virus-derived (LCMV-derived) peptide, gp33 (residues 33-41), presented in the context of $\mathrm{H}-2 \mathrm{D}^{\mathrm{b}}\left(\mathrm{P} 14-\mathrm{Lck}^{\mathrm{WT}}\right.$ and P14-Lck $\left.{ }^{\mathrm{S} 59 \mathrm{~A}}\right)$ mice. When stimulated with gp33, both P14-Lck ${ }^{\mathrm{WT}}$ and P14-Lck ${ }^{559 \mathrm{~A}} \mathrm{CD} 8^{+} \mathrm{T}$ cells expressed similar levels of CD69 and CD25, and these activation markers were suppressed in a CsA-dose dependent manner (Figure 2F). Furthermore, both P14-Lck ${ }^{\mathrm{WT}}$ and P14-Lck ${ }^{\mathrm{S59A}}$ $\mathrm{CD}^{+} \mathrm{T}$ cells produced equivalent amounts of IL- 2 and IF $\mathrm{N}-\gamma$ in the absence of CsA, which was inhibited to the same degree by CsA (Figure 2G). These results demonstrate that expression of $\mathrm{Lck}^{559 \mathrm{~A}}$ has no apparent effect on TCR-signaled upregulation of NFAT activity and susceptibility to inhibition by CsA.

Differential sensitivity of activated WT and Lck ${ }^{559 A} T$ cells to CsA. As shown in Figure 2, activation responses that directly affect NFAT (such as nuclear translocation) and that are downstream targets of NFAT (such as IL-2 and IFN- $\gamma$ production) were affected equally in WT and Lck ${ }^{559 A} \mathrm{~T}$ cells. To investigate a critical and more complex response, we determined the sensitivity of cell proliferation, which relies on the coordinated regulation of cell cycle progression factors, cell division, and the influence of growth and cell survival factors to CsA. Purified CD8 ${ }^{+}$P14-Lck ${ }^{\mathrm{WT}}$ and P14-Lck ${ }^{\mathrm{S} 59 \mathrm{~A}} \mathrm{~T}$ cells were labeled with CellTrace Violet and stimulated with DCs pulsed with gp33 (Figure 3A). Antigen-induced proliferation of T cells of both genotypes was similar in the absence of CsA. However, there was a marked difference in their sensitivities to CsA. The division of WT Lck T cells was largely prevented by $1 \mathrm{ng} / \mathrm{mL}$ CsA whereas a similar degree of inhibition for P14-Lck ${ }^{599} \mathrm{~T}$ cells was only achieved at $30 \mathrm{ng} / \mathrm{mL}$ CsA. Comparing the percentage divided (how many cells committed to division, Figure 3B) and the expansion index (the fold-expansion of the overall culture, Figure 3C) in multiple experiments showed that the $\mathrm{T}$ cells expressing $\mathrm{Lck}^{\mathrm{S} 59 \mathrm{~A}}$ were approximately 10-fold less sensitive to CsA than those expressing Lck ${ }^{\mathrm{WT}}$. This result indicates that although $\mathrm{T}$ cell proliferation is inhibited by CsA when Lck is not a calcineurin target, it is far less effective than when calcineurin can act at the level of TCR proximal signaling.

Inhibition of TCR signaling is an important mechanism of CsA-mediated immunosuppression. The observation that CsA targets $\mathrm{T}$ cell signaling raised the possibility that immunosuppression by CsA might be mediated at least in part by its effects on TCR-mediated but NFAT-independent transcriptional events. One of CsA's main clinical applications is treatment of aGVHD in patients receiving allogeneic stem cell transplants (23-25). We determined the effect of CsA in murine parent-into-F1-induced aGVHD. Lethally irradiated BAF1 $\left(\mathrm{H}-2^{\mathrm{a} / \mathrm{b}}\right)$ mice were transplanted with $\mathrm{T}$ cell-depleted bone marrow (TCD-BM) cells and lymph node cells from WT or $\mathrm{Lck}^{\mathrm{559A}}$ MHC-haploidentical B6 $\left(\mathrm{H}-2^{\mathrm{b}}\right)$ donors. Negative controls were BAF1 mice transplanted with TCD-BM without mature lymph node cells from WT B6 donors. CsA was administered from the time 
A

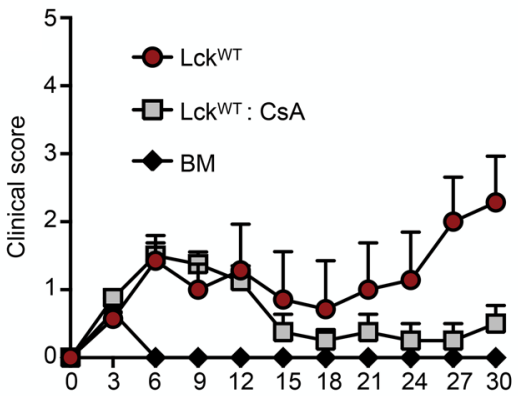

B

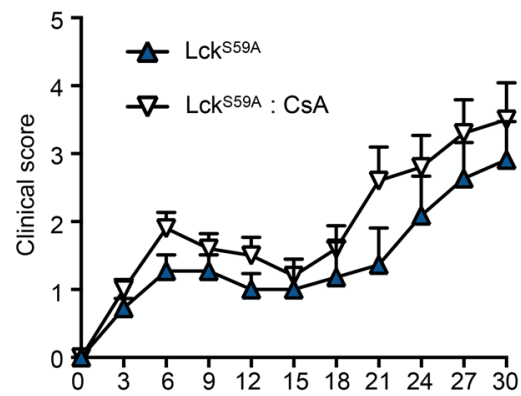

C

\begin{tabular}{|c|c|c|}
\hline \multicolumn{3}{|c|}{ Dead/Total } \\
\hline & Lck $^{\text {WT }}$ & $\mathrm{Lck}^{559 \mathrm{~A}}$ \\
\hline & & \\
\hline & $0 / 8(0 \%)$ & $3 / 10(30 \%)$ \\
\hline
\end{tabular}

D

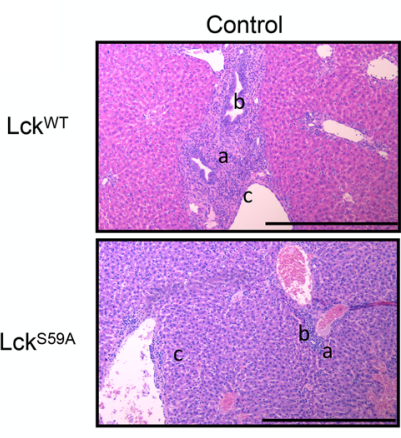

+ CsA

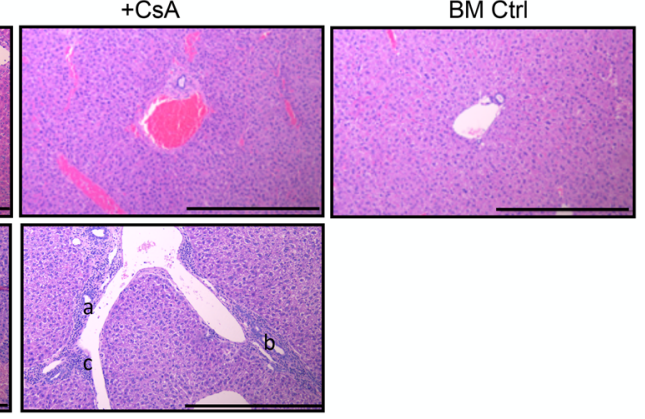

E

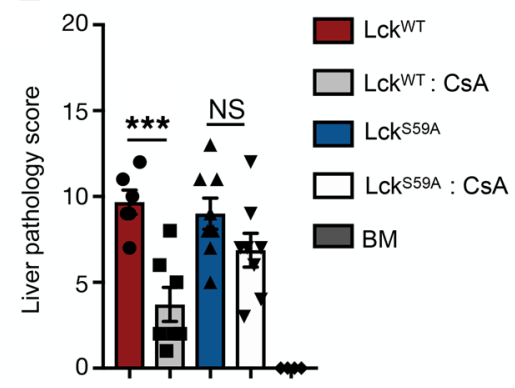

$\mathbf{F}$

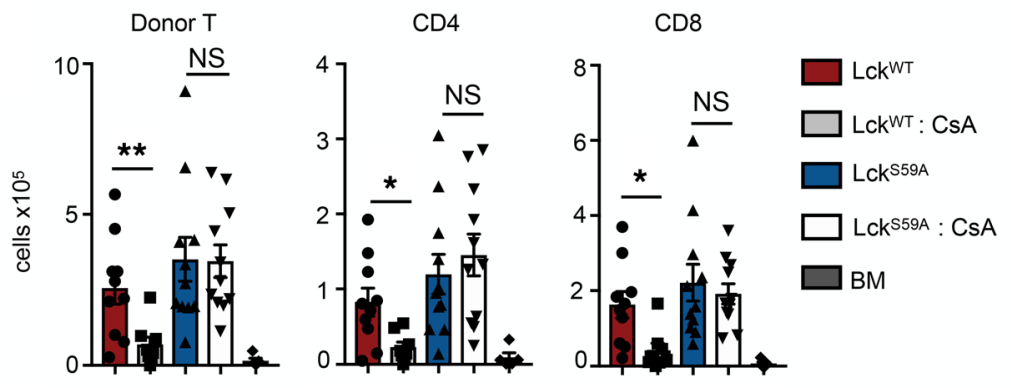

G
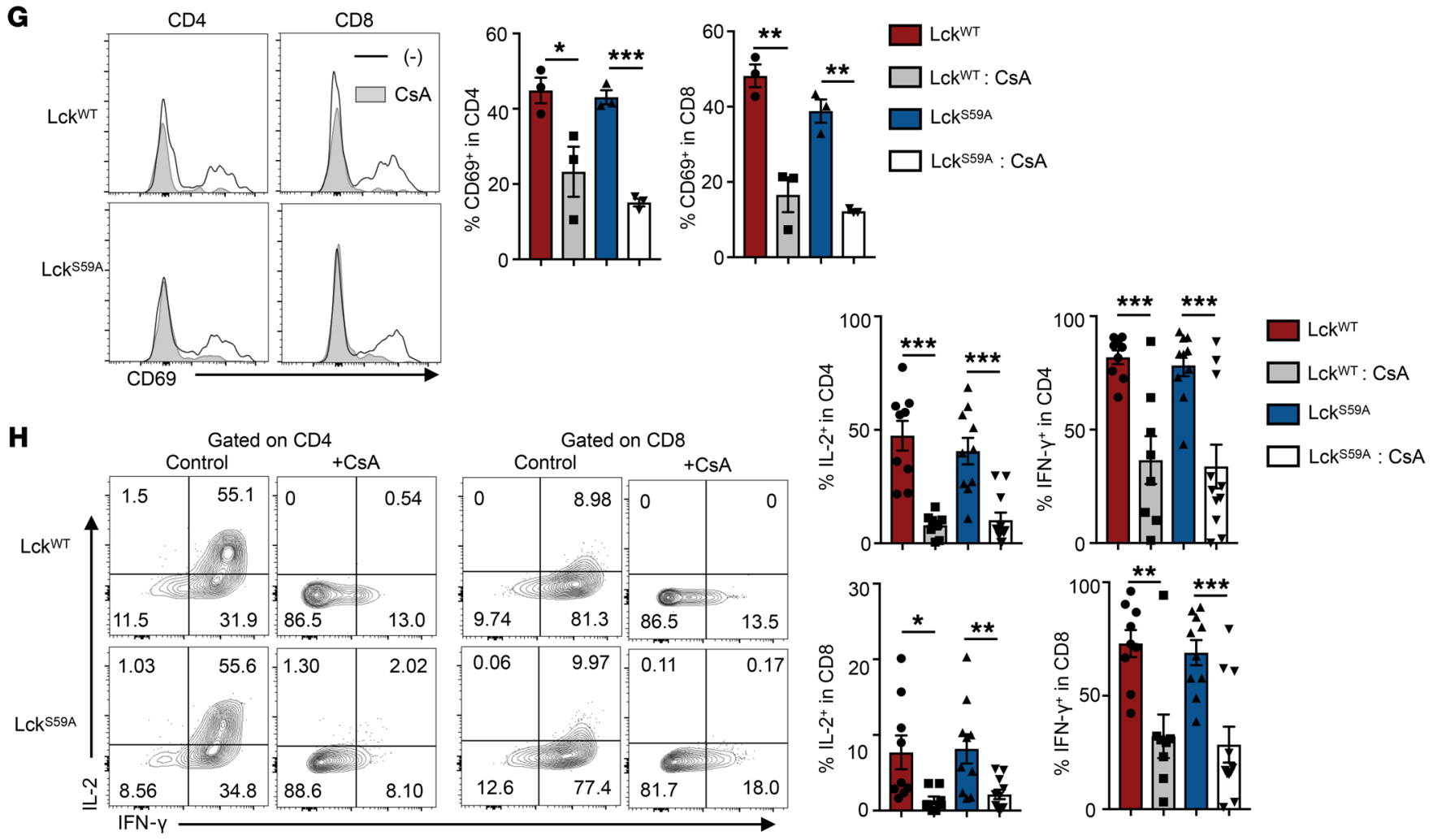
Figure 4. CsA-mediated immunosuppression in aCVHD requires inhibition of TCR signaling. For aCVHD induction, a combination of donor $T$ cell-depleted BM cells and LN cells from B6 WT or B6 $L c k^{559 A}$ mice were injected into irradiated BAF1 mice. CsA was given daily. WT BM cells were given alone as a negative control. (A and B) Mice receiving allogenic WT ( $n$ $=7), \mathrm{WT}+\mathrm{CsA}(n=8), \mathrm{Lck}^{559 \mathrm{~A}}(n=11), \mathrm{Lck}^{559 \mathrm{~A}}+\mathrm{CsA}(n=10)$, and control WT BM $(n=6)$ were scored for aCVHD. (C) The mortality during the course of aGVHD. (D) Samples of liver at 30 days after transplant were stained with H\&E. Livers of recipient mice receiving WT and Lck ${ }^{559 A}$ cells showed aGVHD signs with portal inflammation (a), bile duct lymphocytes and bile duct epithelium (b), and endothelialitis (c). CsA-treated recipient mice receiving WT donor cells had no significant aGVHD signs in the liver, whereas aGVHD signs such as portal inflammation, focal bile duct lymphocytes, and focal endothelialitis were observed in mice receiving Lck $^{559 A}$ cells. Magnification is $\times 100$. Scale bars: $500 \mu \mathrm{m}$. (E) Histopathology scores of mice receiving WT alone $(n=6), \mathrm{WT}+\mathrm{CsA}(n=7)$, Lck ${ }^{559 \mathrm{~A}}$ alone $(n=8)$, or Lck ${ }^{559 \mathrm{~A}}+\mathrm{CsA}(n=$ 8) BM+lymph node cells or control BM alone $(n=4)$ at day 30 . (F) Liver-infiltrating cells were collected from recipient mice receiving WT alone $(n=$ $10), \mathrm{WT}+\mathrm{CsA}(n=8)$, Lck $^{559 \mathrm{~A}}$ alone $(n=11)$, or Lck ${ }^{559 \mathrm{~A}}+\mathrm{CsA}(n=11) \mathrm{BM}+$ lymph node cells or control BM alone $(n=5)$ at day 7 to 8 . The graphs show the mean \pm SEM. ${ }^{*} P<0.05,{ }^{* *} P<0.01$, 2-tailed Student's $t$ test. (G) Representative histograms of CD69 expression on freshly isolated intrahepatic $\mathrm{CD}^{+}$and $\mathrm{CD} 8^{+} \mathrm{T}$ cells from recipient mice at day 7 . The graphs show the mean \pm SEM. ${ }^{*} P<0.05,{ }^{* *} P<0.01,{ }^{* *} P<0.0001$, Student's $t$ test. $(\mathbf{H})$ IL-2 and IFN- $\gamma$ expression by restimulated liver-infiltrating cells from day 7 recipients that had received WT $(n=9), \mathrm{WT}+\operatorname{CsA}(n=8), \operatorname{Lck}^{559 \mathrm{~A}}(n=10)$, or $\mathrm{Lck}^{559 \mathrm{~A}}+\mathrm{CsA}(n=11)$. Representative contour plots of cytokine expression in $\mathrm{CD} 4^{+}$and $\mathrm{CD} 8^{+} \mathrm{T}$ cells are shown. The graphs show the mean $\pm \mathrm{SEM} .{ }^{*} P<$ $0.05,{ }^{* *} P<0.01,{ }^{* * *} P<0.0001$, Student's $t$ test.

of transfer (day 0). The degree of clinical aGVHD was assessed by a scoring system that sums changes in 5 clinical parameters such as weight loss, hunched posture, diarrhea, fur texture, and skin integrity. BAF1 mice receiving either WT or $\mathrm{Lck}^{\mathrm{S59A}} \mathrm{B} 6 \mathrm{~T}$ cells developed signs of aGVHD by 7 days, and thereafter their scores followed a biphasic course, initially diminishing and then increasing, a pattern that has been observed before in semiallogenic transplantation (26). This represented aGVHD, because mice receiving just TCD$\mathrm{BM}$ remained disease free. As expected, CsA substantially reduced aGVHD in mice receiving Lck ${ }^{\mathrm{WT}} \mathrm{T}$ cells, and after 4 weeks the animals remained almost disease free as judged by clinical score (Figure $4 \mathrm{~A}$ ). In mice receiving $\mathrm{Lck}^{\mathrm{S59A}}$ donor cells, on the other hand, more severe clinical scores were observed than in mice receiving WT donor cells (Figure 4B). Surprisingly, CsA actually aggravated aGVHD, as shown by the clinical score and mortality (Figure 4C). We also evaluated aGVHD pathology of liver at 30 days after donor cell transfer. Consistent with clinical scores, liver pathology in mice receiving WT cells was substantially prevented by CsA whereas mice receiving $\mathrm{Lck}^{\mathrm{S59A}}$ donor cells had severe liver damage in both untreated and CsA-treated mice (Figure 4, D and E).

Infiltrating cells from liver, one of the tissues affect in aGVHD mice, were isolated at the early time point of aGVHD (at day 7 after cell transfer) and analyzed. Although there was a considerable range, large numbers of infiltrating donor $\mathrm{T}$ cells were found in the livers of most WT mice, and their numbers were markedly reduced by treatment with CsA (Figure 4F). Although there were similar numbers of infiltrating $\mathrm{Lck}^{\mathrm{559A}}$ donor $\mathrm{T}$ cells, their numbers were unaffected by CsA treatment (Figure $4 \mathrm{~F}$ ). This was true for both $\mathrm{CD}^{+}$and $\mathrm{CD}^{+} \mathrm{T}$ cells. Similar results were obtained in the spleen (Supplemental Figure 1A; supple- mental material available online with this article; https://doi. org/10.1172/JCI147683DS1). The inhibition of NFAT-dependent cytokine productions is a generally accepted mechanism of CsA immunosuppression. To determine if NFAT-dependent functions were unequally affected by CsA in WT and $\mathrm{Lck}^{559 \mathrm{~A}}$ donor $\mathrm{T}$ cells, the expression of the activation marker CD69 and the cytokines IL-2 and IFN- $\gamma$ were assessed in liver-infiltrating T cells (Figure 4, G and H). Each of these NFAT-regulated gene products was suppressed by treatment with CsA in liver-infiltrating WT and Lck ${ }^{\mathrm{S59A}}$ donor T cells. Similar results were found with donor $\mathrm{T}$ cells in the spleen (Supplemental Figure 1, B and C). We also evaluated the liver-infiltrating cells at the end of observation periods (day 30 after donor cell transfer), which were found to be increasing clinical signs of aGVHD. Consistent with clinical scores, we observed a similar number of liver-infiltrating WT and $\mathrm{Lck}^{\mathrm{S59A}}$ donor T cells from CsA-untreated aGVHD mice, and treatment with CsA inhibited WT donor T cell infiltration but not Lck $^{\text {S59A }}$ donor (Supplemental Figure 2A). IL-2 and IFN- $\gamma$ production by intrahepatic WT and $\mathrm{Lck}^{\mathrm{S59A}}$ donor T cells at 30 days was lower even in untreated aGVHD mice as compared with day 7 . There were no differences between CsA-untreated and treated aGVHD mice (Supplemental Figure 2B). This early peak (within 1-2 weeks) of cytokine production in aGVHD mice has been observed before $(27,28)$. Together, these data indicate that CsA-mediated immunosuppression highly relies on inhibition of TCR proximal signaling and not NFAT activation.

CsA exacerbated rather than reduced aGVHD in mice receiving $\mathrm{Lck}^{\mathrm{S} 59 \mathrm{~A}}$ donor cells (Figure $4, \mathrm{~A}-\mathrm{C}$ ). This might be due to CsA-induced reductions in the number of Foxp $3^{+}$Tregs (29), which is probably due to suppression of NFAT-dependent IL-2 production $(20,30)$ and/or direct inhibition of NFAT-regulated Foxp3 expression (31). We found that CsA suppressed the percentage of liver-infiltrating $\mathrm{CD} 4^{+} \mathrm{Foxp}^{+}{ }^{+}$Tregs in aGVHD regardless of whether the recipients had received WT or $\mathrm{Lck}^{\mathrm{S59A}}$ donor cells (Supplemental Figure 2C). Thus, it seems likely that the loss of Treg immunomodulation coupled with the failure of CsA to inhibit $\mathrm{T}$ cell infiltration (Figure $4 \mathrm{~F}$ ) accounts for increased aGVHD in $\mathrm{Lck}^{\mathrm{s59}}$ cell recipients treated with CsA.

CsA reduced perforin expression via the suppression of TCR signaling. Organ damage in aGVHD is mediated by inflammatory mediators and cytotoxic cellular effectors such as Fas/Fas ligand (FasL) and perforin/granzyme cytolytic pathways (32-34). Because Fas/FasL expression is known to be NFAT-dependent $(35,36)$, we focused on the expression of perforin and granzyme $\mathrm{B}$, the expression of which is known to be inhibited by CsA in vitro $(37,38)$ and in vivo $(39)$. Interactions of $\mathrm{CD}^{+}$cytotoxic $\mathrm{T}$ cells (CTLs) with target cells results in the release of perforins and granzymes leading to target cell lysis (40). Cytotoxic granule membranes contain the transmembrane protein CD107a, and its expression on the cell surface is a marker of degranulation (i.e., the delivery of cytotoxic mediators to the extracellular space). As shown in Figure 5A, expression of CD107a was elevated similarly on both WT and $\mathrm{Lck}^{\mathrm{S59A}}$ intrahepatic donor $\mathrm{CD} 8^{+} \mathrm{T}$ cells, regardless of whether the mice received CsA or not. Granzyme B was also upregulated in aGVHD. Its expression was modestly reduced by CsA in mice receiving both WT and $\mathrm{Lck}^{\mathrm{S59A}}$ cells (Figure $5 \mathrm{~B}$ ). Finally, expression of perforin, which is required to create holes in 
A

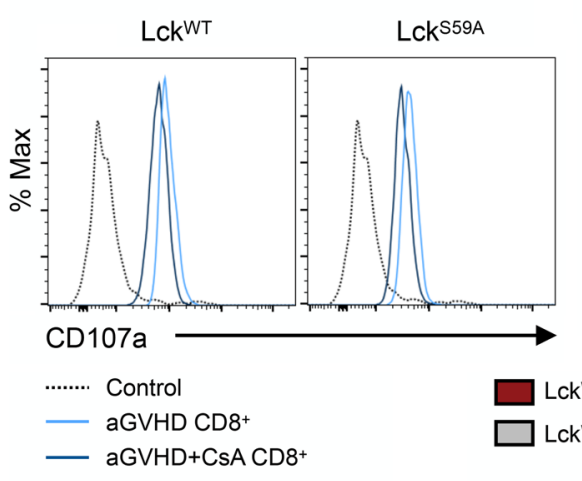

C

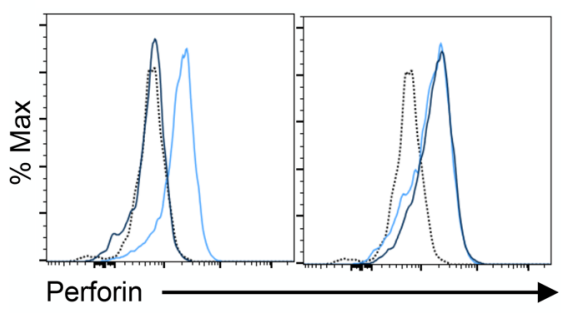

D

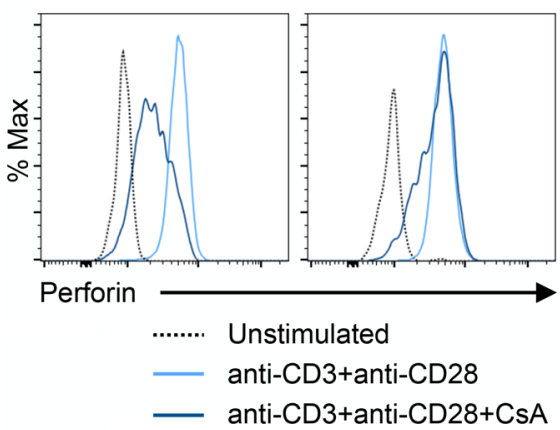

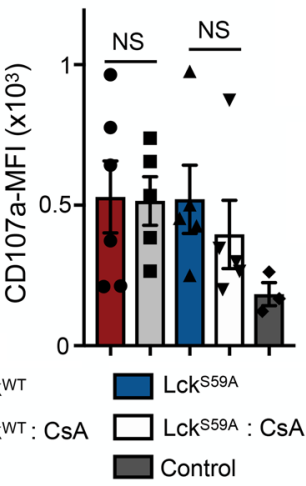

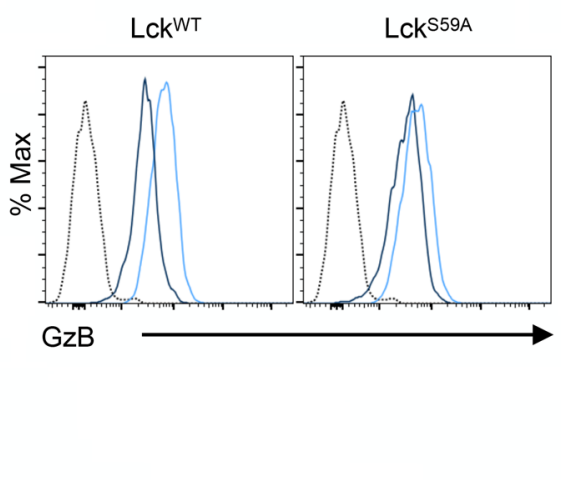

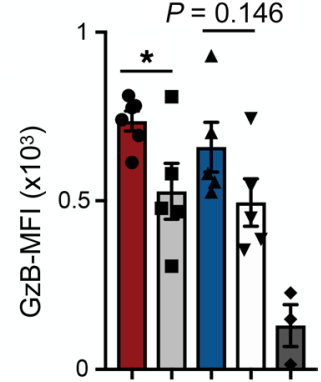

Figure 5. CsA inhibits perforin expression more potently in Lck ${ }^{\mathrm{WT}} \mathbf{T}$ cells. (A-C) Freshly isolated liver-infiltrating cells from recipients receiving B6 WT $(n=6), \mathrm{WT}+$ CsA $(n=5), \operatorname{Lck}^{559 A}(n=5)$, or $\mathrm{Lck}^{559 \mathrm{~A}}+\mathrm{CsA}(n=5)$ donors were stained for CD107a (A), granzyme B (B), and perforin (C) expression. The cells were analyzed by flow cytometry and gated on CD8 ${ }^{+}$. Because of limiting cell numbers, the negative control is TCR- $\beta^{+}$-gated splenocytes from mice that received BM only, and is included with the histograms of both WT and Lck ${ }^{559 A}$ CD8 cells. The error bars represent the mean \pm SEM. (D) Flow cytometric analysis of perforin staining is shown for $\mathrm{CD}^{+}$-gated P14 T cells stimulated on anti-CD3 coated plates and soluble anti-CD28 for 48 hours. The graphs show the relative MFIs of perforin expression compared with activated and CsA-untreated $\mathrm{CD}^{+} \mathrm{T}$ cells. The graphs show the mean \pm SEM of 3 independent experiments. ${ }^{*} P<$ $0.05,{ }^{* *} P<0.01,2$-tailed Student's $t$ test.

the target cell membrane, was strongly inhibited by CsA in WT but not $\mathrm{Lck}^{\mathrm{S59A}} \mathrm{CD}^{+} \mathrm{T}$ cells (Figure $5 \mathrm{C}$ ). Similar results were found in the spleen (Supplemental Figure 3). We conclude that in aGVHD, cytotoxic cell degranulation was calcineurin-independent, whereas perforin expression was sensitive to CsA-mediated inhibition of TCR proximal signaling. This was supported by the in vitro finding that perforin expression in WT but not $\mathrm{Lck}^{\mathrm{559A}} \mathrm{CD}^{+} \mathrm{T}$ cells was sensitive to $10 \mathrm{ng} / \mathrm{mL}$ CsA (Figure 5D). Thus, perforin expression, like upregulation of LFA-1 affinity for ICAM1, is CsA-sensitive due to inhibition of calcineurin activity in the TCR signaling complex.

CsA inhibition of activation-induced LFA-1/ICAM1 adhesion is due to its effects on $T$ cell signaling. LFA-1-ICAM1-dependent T cell adhesion is a transcription-independent biological function (12). Previously, we found that Jurkat cell adhesion to ICAM1-coated plates following anti-CD3-mediated activation was inhibited by pretreatment with CsA, but Lck $^{\mathrm{S} 59 \mathrm{~A}}$-expressing Jurkat cells were partially resistant (12). To determine the mechanism for CsA inhibition of integrin-mediated adhesion in a physiologic setting, we used $\mathrm{CD}^{+} \mathrm{T}$ cells from WT and $L c k^{559 A}$ mice that were crossed to mice bearing the AND transgenic TCR specific for cytochrome $c$ presented by the MHC class II molecule I-E ${ }^{\mathrm{k}}\left(\mathrm{AND}-\mathrm{Lck}^{\mathrm{WT}}\right.$ and
AND-Lck ${ }^{559 \mathrm{~A}}$ mice). Adherent fibroblast-derived DCEK cells that stably express $\mathrm{I}^{-E^{\mathrm{k}}}$ and ICAM1 pulsed with nothing or moth cytochrome $c$ (MCC) peptide were used as APCs. The addition of MCC peptide caused AND-Lck ${ }^{\mathrm{WT}}$ cells to adhere to the ICAM1-expressing DCEK cells, which was largely prevented by preincubation with CsA (Figure 6A). Notably, AND T cells heterozygous for Lck ${ }^{559 A}$ were partially resistant to CsA, whereas $\mathrm{T}$ cells homozygous for Lck $^{559 \mathrm{~A}}$ mouse $\mathrm{T}$ cells were completely insensitive (Figure 6A). This was not specific to $\mathrm{CD} 4^{+} \mathrm{T}$ cells, because the same pattern was observed with MHCI-restricted $\mathrm{CD}^{+} \mathrm{P} 14-\mathrm{Lck} \mathrm{T}$ cells using DCEK-D ${ }^{\mathrm{b}}$ cells, which express $\mathrm{H}-2 \mathrm{D}^{\mathrm{b}}$ (Figure 6B). These results show that with primary $\mathrm{T}$ cells, TCR-induced integrin-mediated adhesion is completely dependent on dephosphorylation of $\mathrm{Lck}^{559}$ by calcineurin, and it is at this level that CsA exerts its effects.

In clinical settings, calcineurin inhibitors such as CsA are typically used to inhibit an ongoing immune response. We asked if CsA can reverse existing $\mathrm{T}$ cell/APC interactions. AND $\mathrm{T}$ cells were cocultured with MCC p-pulsed DCEK cells for 30 minutes to allow adhesion to occur. CsA was then added and the numbers of adherent $\mathrm{T}$ cells were measured over time (Supplemental Figure 4A). A large decrease in the number of adherent T cells was observed as early as 
A

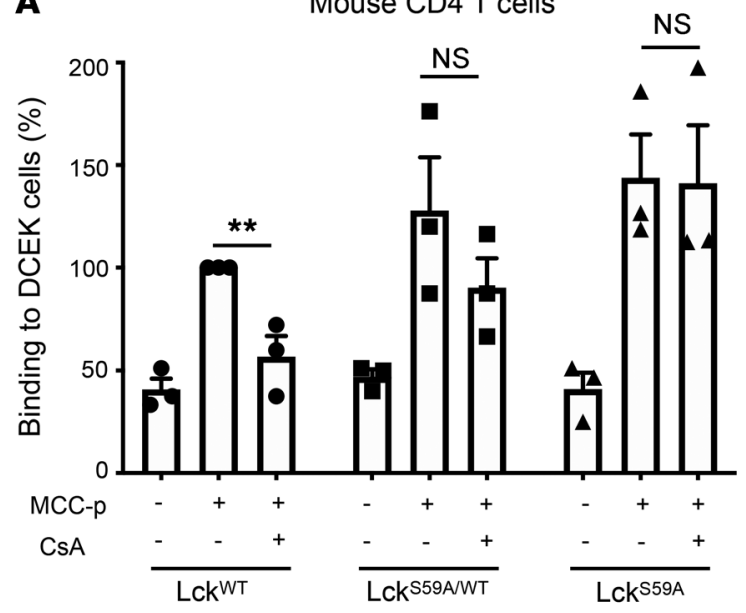

B

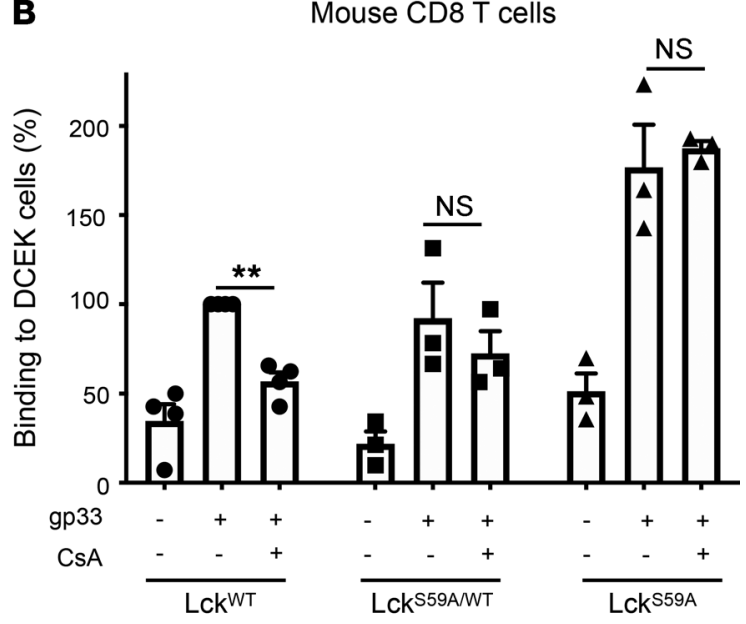

Figure 6. CsA inhibits antigen-induced LFA-1/ICAM1-mediated T/DC adhesion via its affect on TCR signaling. AND or P14 T cells of the indicated genotypes were cultured with antigen-pulsed DCEK or DCEK- $D^{\mathrm{b}}$ cells, respectively, in the presence or absence of CsA for 30 minutes. The binding of WT T cells was considered to be $100 \%$, and the relative number of AND (A) or P14 (B) T cells bound to APCs is shown. Data are shown as the mean \pm SEM of 3 or 4 independent experiments. ${ }^{*} P<0.05,{ }^{* *} P<0.0001$.

10 minutes after calcineurin inhibition. As seen with pretreatment, AND-Lck ${ }^{559 A} \mathrm{~T}$ cell adhesion was not reversed by CsA (Supplemental Figure 4A). The same results were obtained by the same experiments using CD8 ${ }^{+}$P14-Lck ${ }^{\mathrm{WT}}$ and P14- Lck $^{\mathrm{S59A}} \mathrm{T}$ cells (Supplemental Figure 4B). Furthermore, the rapid reversal of established T/APC interactions was not species-specific in that it was observed with primary human T cells (Supplemental Figure 4C). Activation following TCR engagement leads to inside-out signaling, in which the Thr-758 in the intracellular domain of LFA-1 is phosphorylated, which rapidly results in conformational changes in the extracellular portion of the molecule that enhance its affinity for ICAM1 $(41,42)$. Consistent with the functional observations, the increased phosphorylation of LFA- $1^{\mathrm{T} 758}$ rapidly decreased within minutes after the treatment of CsA in primary human T cells (Supplemental Figure 4D). Together, these results indicate ongoing TCR signaling is necessary to maintain high-affinity LFA-1/ICAM1 interactions, and dampening of this by inhibiting calcineurin-mediated dephosphorylation of $\mathrm{Lck}^{\mathrm{559}}$ results in rapid reversal of T/APC adhesion.

$C s A$ inhibits stable antigen-driven $T / D C$ interactions in vivo via its effects on TCR signaling. The upregulation of LFA-1 affinity for ICAM1 is required for the formation of stable $\mathrm{T} / \mathrm{DC}$ conjugates and initiation of effective $\mathrm{T}$ cell activation (41). The finding that CsA inhibits this in vitro by preventing Lck $^{559}$ dephosphorylation (Figure 6 and ref. 12) raised the possibility that such a mechanism could contribute to its immunosuppressive activity in vivo. To visualize physiologic T/DC interactions we labeled naive $\mathrm{T}$ cells from antigen-specific TCR transgenic mice with CellTracker Green CMFDA dye and peptide-pulsed bone marrow-derived DCs with CellTracker Deep Red dye. The labeled DCs were injected s.c. into footpads and allowed to migrate to the draining popliteal lymph nodes (LNs). Eighteen to twenty hours later, labeled $\mathrm{T}$ cells were injected i.v., and after an interval to allow the $\mathrm{T}$ cells to migrate and interact with DCs, the draining popliteal LNs were removed and imaged using 2-photon microscopy. Two hours after injecting P14 CD8 ${ }^{+} \mathrm{T}$ cells, we observed large numbers of both DCs and T cells in the popliteal LNs (Figure 7A and Supplemental Figure 5), and approximately $10 \%$ of T/DC clusters were observed when the DCs had been pulsed with gp33, but few T/DC clusters when the DCs had been pulsed with the irrelevant antigen, OVA-p. At 3 hours, more gp33-pulsed DCs, approximately 20\%, interact with 3 or more P14 CD8 ${ }^{+} \mathrm{T}$ cells (Figure 7, A and B, white arrowheads). Similar percentages of T/DC clusters were observed at 4 and 6 hours (Figure 7B). As with the percentage, the size of the clusters grew from 2 to 3 hours and then remained stable, indicating that T/DC cluster formation matured by 3 hours and thereafter was maintained for at least 3 more hours (Figure $7 \mathrm{C}$ ). To study the effect of calcineurin inhibition, mice were injected with CsA the day before and again at the time of $\mathrm{T}$ cell transfer. Treatment with CsA reduced the number of clusters by 64\% (3 hours) and 60\% (6 hours) (Figure 7, D, E, G, and $\mathrm{H}$ ), as well as T/DC cluster sizes (Figure 7, F and I). The effect of CsA on antigen-specific CD4 ${ }^{+} \mathrm{T} / \mathrm{DC}$ clusters was addressed with MHCII-restricted CD4 ${ }^{+}$AND T cells. We found that at 6 hours after $\mathrm{T}$ cell injection AND CD4 ${ }^{+} \mathrm{T}$ cells formed fewer and smaller clusters with antigen-pulsed DCs than P14 CD8 ${ }^{+}$T cells. Nonetheless, CsA reduced the percentage of antigen-pulsed DCs in T cell clusters and the size of the clusters that did form (Supplemental Figure 6, A-C).

Because the in vitro experiments concluded that CsA rapidly exerts its effects on adhesion, we evaluated the effect of treating the mice with CsA just 1 hour before removing the draining LNs, which would minimize the possibility that any effects could be mediated by inhibition of NFAT and new gene expression. Injection of CsA at 2 hours, at a time before T/DC clusters had matured (Figure 7, B and C), inhibited the percentage of P14 $\mathrm{CD} 8^{+} \mathrm{T} / \mathrm{DC}$ clusters and reduced their size 1 hour later (Figure 7, $\mathrm{J}-\mathrm{L}$ ). To determine if the CsA effect was due to inhibition of calcineurin-mediated Lck ${ }^{559}$ dephosphorylation, we used P14-Lck ${ }^{559 A}$ $\mathrm{T}$ cells. P14-Lck ${ }^{\mathrm{S59} \mathrm{A}} \mathrm{T}$ cells formed clusters with approximately $25 \%$ of gp33-pulsed DCs at 3 hours, similar to what was observed with P14-Lck ${ }^{\text {WT }}$ T cells. Notably, however, P14-Lck ${ }^{\mathrm{S59A}}$ T/DC clusters were unaffected by treatment with CsA (Figure 7, K and L). We conclude that antigen-specific LN T/DC adhesion and clustering requires that calcineurin dephosphorylate of $\mathrm{Lck}^{559}$ in the TCR signaling complex, which is prevented by CsA. 
A

gp33
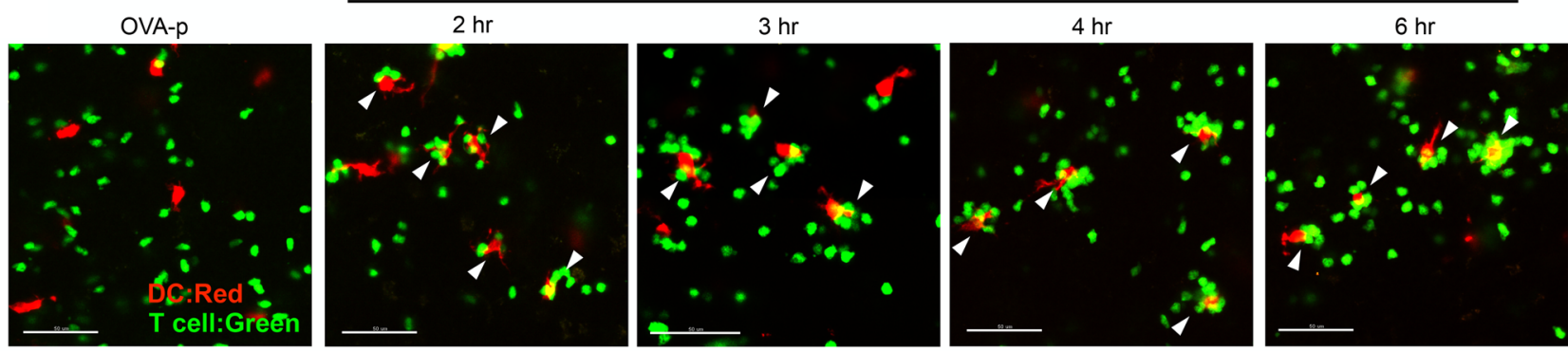

B
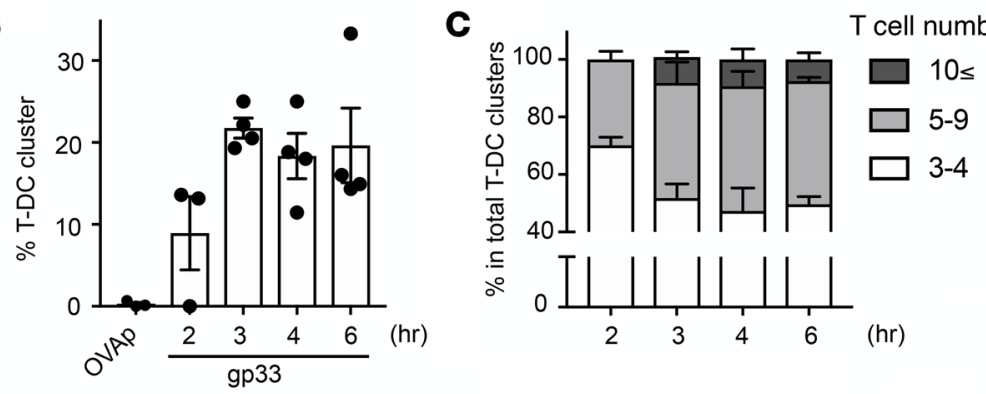

D
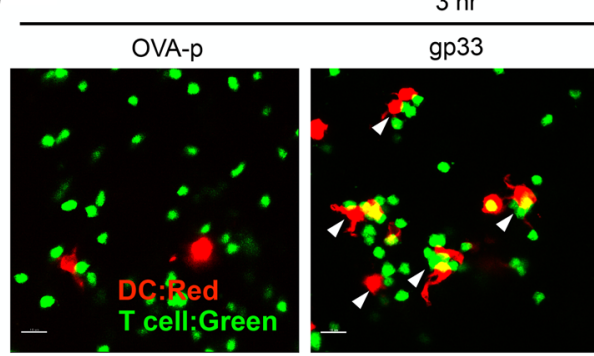

G

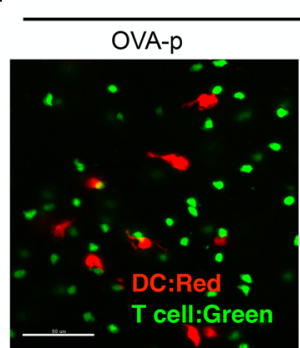

J
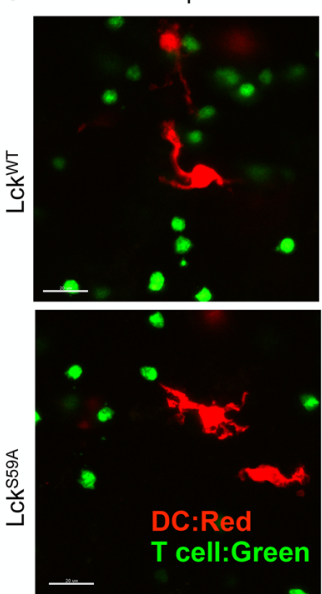

gp33

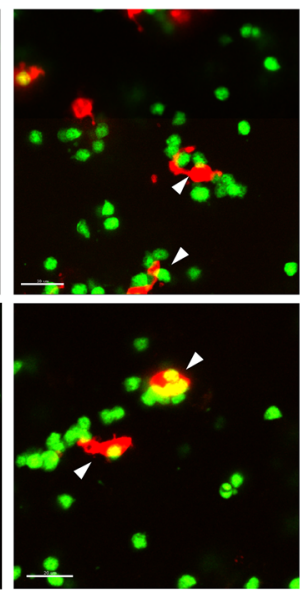

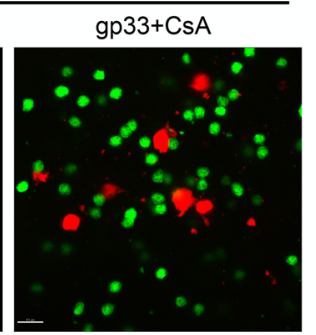
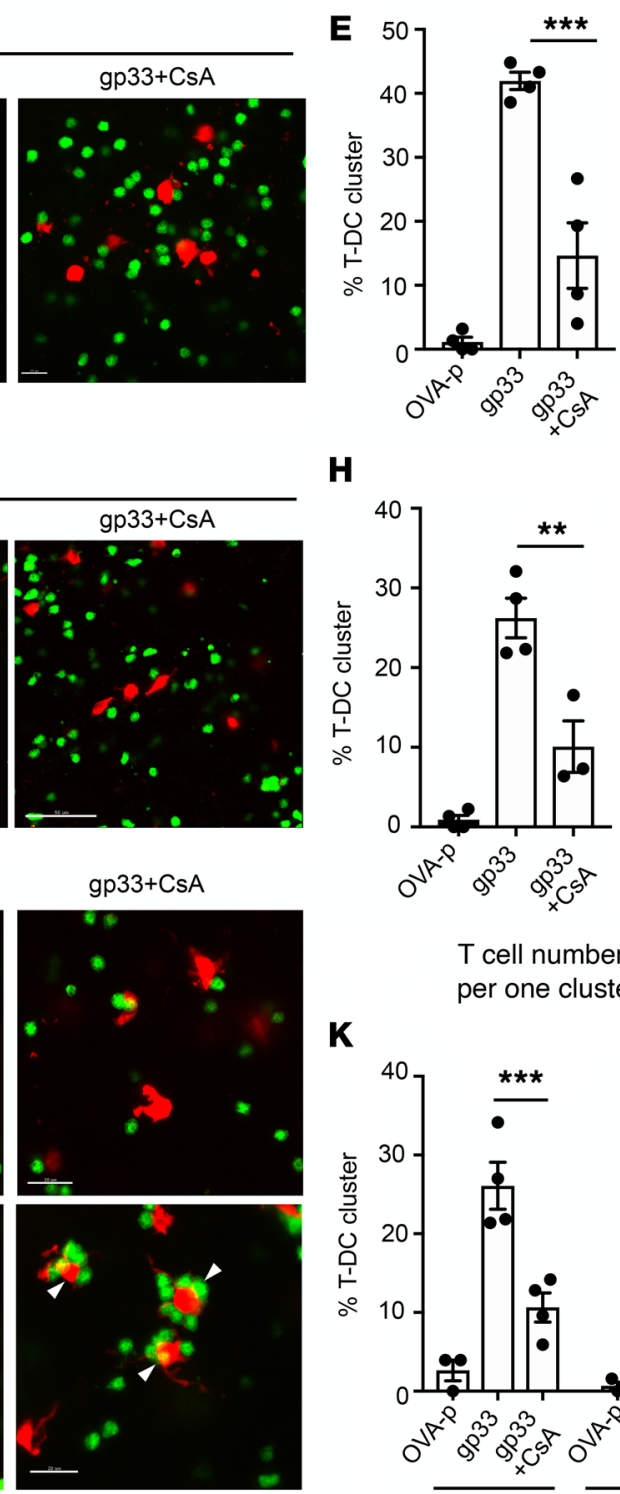

H

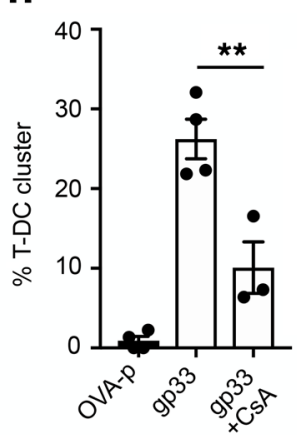

T cell numbers per one cluster

K

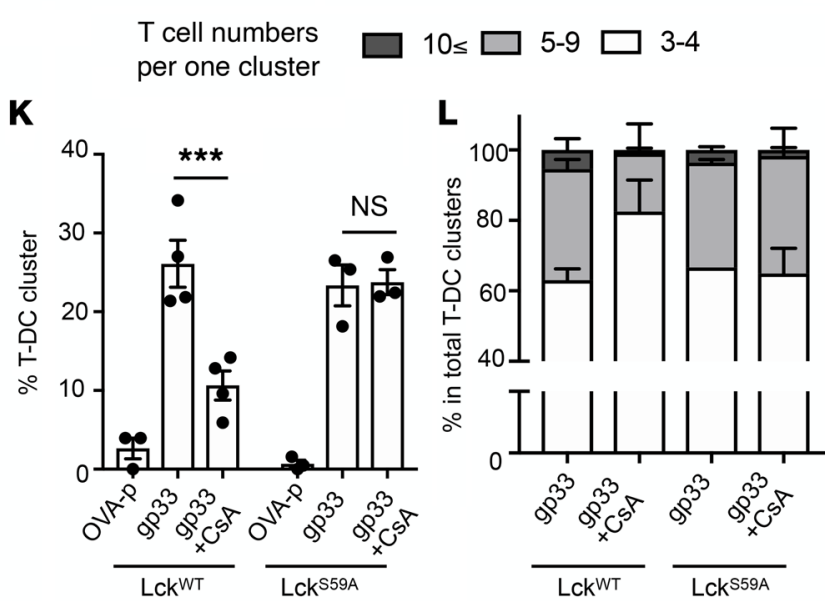

F $100-\begin{array}{r}\text { T cell numbers } \\ \text { per one cluster }\end{array}$

$\square 10 \leq$

$\square$ 5-9

$\square$ 3-4 
Figure 7. T/DC interactions are inhibited by CsA via suppression of TCR proximal signaling. Mice were injected in the footpad with gp33 or OVA-p pulsed DCs labeled with Deep Red Dye. After 18 to 20 hours, recipients were injected i.v. with green CMFDA-labeled P14 WT or Lck ${ }^{559 A}$ T cells. pLNs were collected at the indicated times, cleared, and imaged by 2-photon microscopy. (A) Example images ( $20 \mu \mathrm{m}$ thick) at the indicated times are shown (DCs are red, P14 T cells are green). Arrows (white) indicate T/ DC clusters. (B) The percentage of T/DC clusters as analyzed by Imaris software. Data were pooled from 3 or 4 experiments. (C) The proportion of small ( $3-4$ cells), medium (5-9 cells), and large ( 10 or more cells) clusters in the total number of T cell clusters. The number of T cells per cluster as analyzed by Imaris software. Data were pooled from 2 to 4 independent experiments. (D-I) Mice were injected i.p. with CsA or PBS at the time of $D C$ transfer and again the time of $T$ cell transfer. $\mathrm{pLNs}$ were removed at 3 (D-F) or 6 (G-I) hours after T cell injection and imaged. Representative images are shown in (D) and (C). The percentage of T/DC clusters (E and $\mathbf{H}$ ) and the number of T cells per cluster ( $\mathbf{F}$ and $\mathbf{I}$ ) were analyzed by Imaris software. Data were pooled from 3 to 4 independent experiments ( $E$ and $\mathbf{H}$ ) or 3 independent experiments ( $\mathbf{F}$ and $\mathbf{I})$. (J-L) CsA was injected 1 hour before collecting $\mathrm{pLNs}$. Representative images are shown in (J). The percentage of T/DC clusters (K) and the number of T cells per cluster $(\mathbf{L})$ were determined with Imaris software. Data were pooled from 3 or 4 independent experiments (K) or 3 independent experiments (L). The graphs show the mean \pm SEM. ${ }^{*} P<0.05,{ }^{* *} P<0.01,{ }^{* *} P<0.0001$ by 2 -way ANOVA with Tukey's multiple-comparison post hoc test.

\section{Discussion}

A series of studies in the early 1990s provided a molecular basis for the immunosuppressive activity of CsA: (a) CsA inhibits NFAT nuclear translocation (7), (b) $\mathrm{Ca}^{2+} / \mathrm{CaM}$-regulated calcineurin dephosphorylates and allows NFAT nuclear translocation (43, 44 ), and (c) calcineurin catalytic activity is inhibited by CsA (8). These are the basis of the paradigm that CsA and other CNIs exert their immunosuppressive effects by inhibiting the upregulation of NFAT-dependent genes (45). The recent finding that calcineurin, as a component of the TCR signaling complex, positively regulates $\mathrm{T}$ cell activation by preventing the inhibitory phosphorylation of $\mathrm{Lck}^{\mathrm{S59}}$ provides another potential mechanism by which CNIs might immunosuppress (12). In the present study, mice expressing Lck ${ }^{559 \mathrm{~A}}$ (nonphosphorylatable at serine 59 and thus not a calcineurin target) were used to ask which T cell effector pathways were CsA-sensitive (presumably NFAT-dependent) and which were resistant (TCR-dependent and NFAT-independent). As expected, CsA inhibited production of cytokines known to be transcriptionally upregulated by NFATs in activated $\mathrm{Lck}^{\mathrm{S59A}} \mathrm{T}$ cells. However, 2 events critical for induction of $\mathrm{T}$ cell effector function, activation-induced LFA1-dependent T/DC adhesion and upregulation of the cytotoxic pore-forming molecule perforin, were either entirely or partially insensitive to CsA. Furthermore, and contrary to the current view of CsA's primary mechanism of action, despite inhibiting NFAT-dependent targets, CsA was ineffective in treating aGVHD in mice receiving Lck $^{\mathrm{S} 59 \mathrm{~A}}$ allo-reactive T cells. These results paint a more complex picture of how CNIs affect immune response with a focus on their ability to disrupt early TCR signaling.

aGVHD is a major complication of allogeneic hematopoietic stem cell transplantation (HSCT), a well-established therapy for malignant and nonmalignant hematologic diseases (46). aGVHD is a $\mathrm{T}$ cell-mediated disease with damage to organs such as liver, skin, and the gastrointestinal tract. CNIs are among the standard therapies because of their potent inhibition of $\mathrm{T}$ cell functions.
The activation of antigen-specific $\mathrm{T}$ cells requires that they form stable interactions with antigen-bearing APCs via binding of $\mathrm{T}$ cell LFA-1 to APC cell-surface ICAM1 $(41,47)$. LFA-1 is a constitutively expressed heterodimeric adhesion molecule composed of 2 chains, CD11a $\left(\alpha_{\mathrm{L}}\right)$ and CD18 $\left(\beta_{2}\right)$, which upon T cell activation rapidly undergo conformational changes that increase the affinity for ICAM1 (41). Antibody blockade of LFA-1 or knockout of CD18 inhibits antigen-induced $\mathrm{T}$ proliferation, cytokine production, and differentiation into Th1 cells $(47,48)$. Consistent with in vitro observations, blockade of LFA-1 ameliorated disease in in vivo disease models such as acute and chronic GVHD (49, 50), collagen-induced arthritis (51), and EAE (52). In the case of aGVHD, mice receiving CD11a ${ }^{-/-}$or $\mathrm{CD} 18^{-/-}$donor $\mathrm{T}$ cells had markedly less morbidity and mortality compared with recipients of WT T cells $(53,54)$, and treatment with anti-ICAM1 or antiLFA-1 antibodies also reduced aGVHD severity and enhanced survival $(49,50)$. We previously reported that CNIs inhibited phosphorylation of CD18 ${ }^{\mathrm{T} 758}$ as well as Jurkat and primary $\mathrm{T}$ cell adhesion to ICAM1-coated wells or ICAM1-expressing APCs, respectively. Although suggestive, the question of whether CNIs prevent one of the very earliest and NFAT-independent (12) steps in $\mathrm{T}$ cell activation in vivo has not been addressed. Using 2-photon lymph node imaging we were able to directly demonstrate time-dependent increases in antigen-specific $\mathrm{T}$ cell clustering around antigen-bearing DCs and found that it was indeed sensitive to CsA, even when given only 1 hour before measurement. Importantly, CsA was unable to inhibit antigen-specific $\mathrm{Lck}^{\mathrm{559A}}$ T/DC clustering, which correlated with its relative inability to control aGVHD. Given the central importance of T/DC adhesion in both normal and pathological immune responses, it seems highly likely that much of the effectiveness of CNIs in treating aGVHD is via their ability to hinder TCR-dependent/NFAT-independent LFA-1-mediated T/APC interactions.

One of the cellular mechanisms leading to tissue damage in aGVHD is T cell cytotoxicity (32). The major mechanism by which $\mathrm{CD}^{+} \mathrm{T}$ cells kill is directed release of granules containing cytotoxic molecules such as perforin and granzymes. Perforin creates a pore-like structure in the plasma membrane of target cells and is indispensable for the delivery of granzymes and other lethal granule products (55). $\mathrm{CD} 8^{+} \mathrm{T}$ cells from perforin-deficient mice have significantly reduced cytotoxic activity and the animals are unable to clear viral infections (56). CNIs are known to inhibit the expression of perforin and cytotoxic granule-mediated killing (37). Because the Prf1 promoter contains an NFAT binding site, inhibition of NFAT signaling has been thought to be the molecular explanation for its CsA sensitivity (57). However, we found that expression of perforin in $\mathrm{Lck}^{\mathrm{S59A}} \mathrm{CD}^{+} \mathrm{T}$ cells, both in vitro and in the tissue of mice undergoing aGVHD, was relatively insensitive to CsA. This result is in agreement with another study in which activated NFAT1-deficient $\mathrm{CD}^{+} \mathrm{T}$ cells had cytolytic activity comparable to activated WT CD8 ${ }^{+}$T cells (58). Furthermore, although a marked decrease in killing ability was observed in activated NFAT2-deficient T cells, transcript levels of Prf1 genes encoding the most prominent perforins in CTLs were unaffected (58). The question then arises of how does CsA inhibit perforin expression. RNA-seq analysis of Run $\times 3^{-/-} \mathrm{P} 14 \mathrm{CD}^{+}$effector T cells purified from mice infected with LCMV-Armstrong suggested that Runx3 
controls genes related to cytotoxic machinery, including Prf1 and Gzm (59). Furthermore, using Run $x 3^{-/-} \mathrm{CD}^{+} \mathrm{T}$ cells, it was shown that Runx 3 cooperates with Eomes to bind the Prf1 locus following stimulation, resulting in perforin upregulation (60). Runx3 is highly expressed in resting peripheral $\mathrm{CD}^{+} \mathrm{T}$ cells whereas Eomes is induced by TCR stimulation. Thus, it is possible that inhibitory Lck $^{559}$ phosphorylation disrupts NFAT-independent signaling pathways that upregulate Eomes, which would account for the insensitivity of $\mathrm{Lck}^{\mathrm{559A}} \mathrm{T}$ cells and mice to CsA.

Because of their importance in regulating many activation-induced T cell genes, NFATs have been targeted by several different approaches. Although indirect inhibition by CNIs is most common, agents that directly target NFATs have been developed and have met with some success in animal models. The NFAT inhibitory peptide VIVIT contains a region mimicking the major calcineurin-docking site on NFATs, and prevents calcineurin binding without impairing its catalytic activity (19). Cell-permeable VIVITbased peptides reduced rejection of allogeneic islet transplants in mice (61), alleviated allergic airway inflammation and hyper-responsiveness in ovalbumin-induced asthma (62), and ameliorated experimental autoimmune encephalomyelitis (EAE) (63). Although these results demonstrate that inhibitors of NFAT can immunosuppress in vivo, a direct comparison with CNIs such as CsA and FK506 was not made and so relative efficacies could not be assessed. We found that despite equivalent NFAT inhibition in WT and $\mathrm{Lck}^{\mathrm{S59A}} \mathrm{T}$ cells, aGVHD in mice receiving the latter was resistant to CsA, demonstrating that the beneficial effect of calcineurin inhibition was largely due to inhibition of TCR signaling events. The differences between this and the earlier reports may be explained in part by differences in disease pathophysiology. Perforin-dependent cytotoxicity is a major factor in aGVHD survival and pathophysiology (64-66). One of the notable findings in the present study was that CsA reduced perforin expression in tissue-infiltrating WT but not $\mathrm{Lck}^{\mathrm{559A}} \mathrm{CD}^{+} \mathrm{T}$ cells even though NFAT-dependent cytokines such as IFN- $\gamma$ and IL-2 were equally inhibited. The response of perforin expression but not cytokine production to CsA correlated with the immunopathology scores. In contrast, $\mathrm{CD} 8^{+} \mathrm{T}$ cells and their perforin-dependent cytotoxicity appear to have a less important role in EAE (67) and asthma (68), where the pathology of these diseases is highly dependent on cytokines. The ability of CNIs to inhibit TCR signaling and thus perforin expression might be especially important in diseases in which cytotoxicity is a major component.

Our data indicate calcineurin contributes to distinct molecular pathways depending on whether it acts at the level of the TCR (T cell proliferation, LFA-1 activation, perforin production) or NFATs (cytokine production, such as that of IL-2 and IFN- $\gamma$ ). Previous reports have demonstrated that TCR signaling pathways initiating cytokine production and $\mathrm{T}$ cell proliferation are separable, with a TCR/Vav/Notch-driven pathway leading to c-Myc expression and cell proliferation but not cytokine production (69). Given that Notch has also been shown to interact with Lck (70), it possible that the effect of calcineurin in the TCR is a part of the TCR/Vav/ Notch pathway. Previous data using the NFAT-specific inhibitor VIVIT are also consistent with the possibility that some CsA-sensitive events are driven by NFAT-independent mechanisms. For example, CsA-sensitive cytokines such as IL-2, IL-13, IL-3, TNF- $\alpha$, and GM-CSF are inhibited by VIVIT, whereas TNF- $\beta$ and LT- $\beta$ are not (19). Furthermore, whereas CsA inhibited Th1, Th2, and Th17 differentiation and generation of induced Tregs (iTregs), VIVIT inhibited only Th1 and Th17 differentiation without affecting Th2 and iTregs (63). Further studies with $\mathrm{Lck}^{\mathrm{S} 59 \mathrm{~A}} \mathrm{~T}$ cells should allow a better appreciation of which calcineurin targets regulate different CsA-sensitive signaling pathways.

The results in this report demonstrated that the effective therapeutic effect of CsA in aGVHD is largely independent of NFAT inhibition but rather due to inhibition of proximal $\mathrm{T}$ cell signaling and its downstream sequelae. In particular, 2 TCR-dependent and NFAT-independent mechanisms of CsA's immunosuppression were observed, inhibition of LFA-1-dependent T/DC adhesion and perforin expression. NFAT expression is not restricted to $\mathrm{T}$ cells, and a major limitation of CNI treatment is off-target toxicity, in particular kidney damage, but also hypertension, dyslipidemias, and neurological abnormalities $(71,72)$. It is conceivable that approaches that inhibit calcineurin in the TCR complex, for example by disrupting its recruitment to the signaled receptor, without globally affecting NFAT activation might be an effective intervention with fewer side effects in autoimmune diseases.

\section{Methods}

Mice. C57BL/6 (B6, H-2 $)$, B10.A (H-2 $\left.{ }^{\mathrm{a}}\right)$, and Rag2 $2^{-/-}$AND TCR$\alpha \beta$ transgenic mice used for the studies were bred in our facility. P14 TCR-transgenic mice were obtained from The Jackson Laboratory and $L c k^{559 A}$ knock-in mice (international strain designation C57BL/6-Lck ${ }^{\text {tm3Mal }}$, ref. 14) were from the European Mouse Mutant

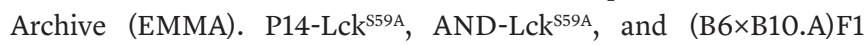
(termed BAF1) mice were obtained by breeding in our facility. Experiments used both male and female mice between 6 and 12 weeks of age. For aGVHD, donors and recipients were sex matched.

Antibodies and reagents. For immunoblot analysis, rabbit antibodies were purchased from Cell Signaling Technologies: anti-phosphorylated ZAP-70 ${ }^{\mathrm{Y} 319}$ (catalog 2701), anti-phosphorylated PLC $\gamma 1^{\mathrm{Y} 783}$ (catalog 2821), anti-phosphorylated LAT ${ }^{\mathrm{Y} 171}$ (catalog 3581), anti-phosphorylated ZAP-70 ${ }^{\mathrm{Y} 493}$ (catalog 2704), anti-ZAP-70 (clone 99F2; catalog 2705), anti-phosphorylated SRC ${ }^{\mathrm{Y} 416}$ (catalog 2101), anti-phosphorylated p38 ${ }^{\mathrm{T} 180 / \mathrm{Y} 182}$ (catalog 9211), and anti-p38 MAPK (catalog 9212); anti-phosphorylated CD18 ${ }^{\mathrm{T} 758}$ (catalog 63388) was purchased from Abcam. These antibodies were used at a dilution of 1:1000. The following antibodies were used for flow cytometric analysis at a concentration of 1:100: FITC-conjugated anti-CD8 $\alpha$ (clone 53-6.7, catalog 11-0081-85),PE-conjugated anti-IFN- $\gamma$ (clone XMG1.2, cata$\log$ 12-7311-41), anti-granzyme B (clone NGZB, catalog 12-8898-82), PE-Cy7-conjugated anti-CD69 (clone H1.2F3, catalog 25-0691-82), APC-conjugated anti-H-2Kb (clone AF6-88.5.5.3, catalog 17-595880), anti-IL-2 (clone JES6-5H4, catalog 17-7021-81), anti-perforin (clone eBio-OMAK-D, catalog 17-9392-80), anti-Foxp3 (clone FJK-16s, catalog 17-5773-82), and eFluor450-conjugated anti-CD4 (clone GK1.5, catalog 48-0041-82) from eBioscience; FITC-conjugated anti-CD107a (clone 1D4B, catalog 553793) and anti-CD4 (clone RM4-5, catalog 553047), PE-conjugated anti-CD25 (clone PC61, catalog 553866), PE-Cy7-conjugated anti-CD4 (clone RM45 , catalog 552775), APC-conjugated anti-CD8 $\alpha$ (clone 53-6.7, catalog 553035), AF700-conjugated anti-TCR- $\beta$ (clone H57-597, catalog 560705), Per-CP-Cy5.5-conjugated anti-CD4 (clone RM4-5, 
catalog 550954), BV510-conjugated anti-CD8 $\alpha$ (clone 53-6.7, catalog 563068), and anti-Fc $\gamma \mathrm{RII} / \mathrm{III}$ receptor (clone 2.4G2) from BD Biosciences; PE-Cy7-conjugated anti-H-2Db (clone KH95, catalog 111516) from BioLegend; and PE-conjugated anti-NFAT1 (clone D43B, cata$\log$ 14335) from Cell Signaling Technology. The following antibodies were used for the activation of human or mouse T cells: anti-human CD3 functional grade purified (clone OKT3, catalog 16-0037-85) from eBioscience; anti-mouse CD3 (clone 145-2C11, catalog 100302) and anti-mouse CD28 (clone 37.51, catalog 102102) from BioLegend; goat anti-Armenian hamster IgG $(\mathrm{H}+\mathrm{L})$ (catalog 127-005-160), and donkey anti-mouse IgG (H+L) (catalog 715-005-150) from Jackson Immunoresearch. The following reagents were used for intracellular staining: Fixation/Permeabilization Solution Kit (BD Cytofix/Cytoperm, catalog 554714) and Protein Transport Inhibitor containing Monensin (catalog 554724) were purchased from BD Biosciences; Foxp3/Transcription Factor Staining Buffer Set (catalog 00-5523-00) from eBioscience. Moth cytochrome $c$ (MCC) peptide 88-103 (ANERADLIAYLKQATK), gp33 peptide 33-41 (KAVYNFATM), and OVA peptide 257-264 (SIINFEKL, OVA-p) were purchased from Peptide 2.0. Recombinant human ICAM1-CD54-Fc chimera (catalog 720IC-050) was purchased from $R \& D$ Systems. CsA for in vitro experiments was obtained from MilliporeSigma (catalog C3662) and CsA (Sandimmune Injection) for in vivo experiments was purchased from Novartis. Murine GM-CSF (mGM-CSF, catalog 315-03) was obtained from Peprotech. EasySep Mouse T Cell Isolation Kits (catalog 19851) were purchased from STEMCELL Technologies. Enhanced Human T Cell Immunocolumns (catalog CL100) and Lympholyte-M were from Cedarlane. Mouse IL-2 ELISA Ready-SET-Go Kit was obtained from eBioscience. IFN- $\gamma$ Mouse Uncoated ELISA Kit (catalog 88-7314-86), Lipofectamine 2000 Transfection Reagent (catalog 11668019), CellTracker Green CMFDA Dye (catalog C7025), CellTracker Deep Red Dye (catalog C34565), CellTrace Violet cell proliferation kit (catalog C34557) and LIVE/DEAD Fixable Blue Dead Cell Stain Kit, for UV excitation (catalog L23105) were from Invitrogen. SuperSignal West Femto Maximum Sensitivity Substrate (catalog 34096) and SuperSigna1 West Dura Extended Duration Substrate (catalog 34076) were purchased from Thermo Fisher Scientific. 0.25\% Trypsin-EDTA (catalog 25200056) and HBSS (catalog 14175103) were from Gibco. The following reagents were used for tissue clearing for imaging studies: FocusClear solution (catalog FC-101) and MountClear solution (cata$\log$ MC-301) from CelExplorer Lab.

$T$ cell isolation. Mouse T cells were purified from LNs of WT and $L c k^{559 A}$ knock-in mice with the EasySep Mouse T Cell Isolation Kit. Human $\mathrm{T}$ cells were isolated from buffy coats of healthy volunteers (NIH Blood Bank) using Enhanced Human T Cell Immunocolumns according to the manufacturer's instructions.

Immunoblot analysis. Purified T cells were pretreated with CsA $(100 \mathrm{ng} / \mathrm{mL})$ for 30 minutes at $37^{\circ} \mathrm{C}$ followed by incubation with soluble anti-CD3 (clone 145-2C11) on ice. Anti-CD3 was then cross-linked with anti-hamster IgG for the indicated times, and the cells were lysed in $1 \%$ Triton X-100 lysis buffer supplemented with protease and phosphatase inhibitors (Roche) for 30 minutes on ice and centrifuged for 20 minutes at 13,000g. The supernatant was boiled in SDS sample buffer for 10 minutes. Samples were subjected to SDS-PAGE and transferred to nitrocellulose membranes (Trans-Blot Turbo, Bio-Rad). The membranes were incubated for 60 minutes in $2 \%$ skim milk powder in Tris buffered saline (TBS) with $0.1 \%$ Tween (TBS-T) and then incubated overnight at $4^{\circ} \mathrm{C}$ with the indicated primary antibodies. Membranes were then washed with TBS-T and incubated with the appropriate HRP-conjugated anti-rabbit Ig secondary antibodies for 1 hour at room temperature. Immunodetection was performed by enhanced chemiluminescence (SuperSignal West Femto and SuperSignal West Dura).

Flow cytometry. Cells were washed once in cold PBS containing $0.5 \%$ BSA and $0.1 \% \mathrm{NaN}_{3}$ (FACS buffer) and incubated with anti-Fc $\gamma$ RII/III receptor (2.4G2) to prevent nonspecific antibody binding. Surface staining was performed with the indicated antibodies for 30 minutes at $4^{\circ} \mathrm{C}$ in FACS buffer using the reagents listed in the Key Resources Tables. For intercellular staining, cells were surface-stained prior to being treated with BD Cytofix/Cytoperm Fixation/Permeabilization Solution Kit or eBioscience Foxp3/Transcription Factor Staining Buffer Set. Fixation/permeabilization was performed according to manufacturers' recommendations. Cells were acquired with a LSRII (BD Biosciences) and analyzed with FlowJo software. For image flow cytometry, T cells were stimulated with anti-CD3 cross-linked with anti-hamster IgG in the presence or absence of CsA $(100 \mathrm{ng} / \mathrm{mL})$ for 30 minutes and surface-stained, then permeabilized and fixed with the Foxp3/Transcription Factor Staining Buffer Set. DAPI was added before cell acquisition. Cells were acquired with an ImageStreamX Mark II. Quantitative analysis of nuclear translocation of NFAT1 was performed with IDEAS image-analysis software (ImageStream/ Amnis). NFAT nuclear translocation is expressed as the percent of cells that exhibit a similarity morphology score greater than 1 . Amnis IDEAS software calculates the similarity feature as a pixel-by-pixel correlation between the channel containing the NFAT image and the DAPI channel with the nuclear image and is expressed as the log-transformed Pearson's correlation coefficient.

Cytokine measurements in vitro. Purified T cells were stimulated with plate-coated anti-CD3 $(10 \mu \mathrm{g} / \mathrm{mL})$ and soluble anti-CD28 $(2 \mu \mathrm{g} /$ $\mathrm{mL}$ ) for 18 hours in RPMI 1640 supplemented with $10 \%$ heat-inactivated fetal bovine serum, $100 \mathrm{mg} / \mathrm{mL}$ gentamicin, $4 \mathrm{mM} \mathrm{L}$-glutamine, and $50 \mu \mathrm{M}$ 2-mercaptoethanol (complete medium). IL-2 and IFN- $\gamma$ levels in the supernatant were measured by ELISA, according to the manufacturer's recommendations.

Preparation of bone marrow-derived dendritic cells (BMDCs). BM cells from B6 or B10.A mice were harvested from bilateral femurs and tibias and red cells were lysed with ammonium chloride. BM cells were initially cultured in 6-well plates with $2.5 \mathrm{~mL}$ complete medium containing $100 \mathrm{ng} / \mathrm{mL} \mathrm{mGM-CSF}$. At day 3, the medium was added, and half the medium in each culture was changed every 3 days until the cells were used for experiments. Loosely adherent cells were collected as BMDCs; $65 \%$ or more of the nonadherent cells expressed CD11c at day 8 to 12 . To activate and upregulate expression of MHC and costimulatory molecules, BMDCs were stimulated with $1 \mu \mathrm{g} / \mathrm{mL}$ LPS for 4 hours and then washed twice with complete medium before in vivo and in vitro experiments.

Quantitating cell division. Purified P14 T cells were washed twice with PBS, and CellTrace Violet (CTV) in PBS was added to a cell suspension at a 1:1 volume with a final dilution of $5 \mu \mathrm{M}$ CTV. Samples were incubated for 20 minutes at $37^{\circ} \mathrm{C}$ in the dark and then washed with PBS. The labeled T cells were cultured at a density of $2 \times 10^{5}$ cells/ well with $2 \times 10^{4}$ LPS-stimulated BMDCs and $10 \mathrm{nM} \mathrm{gp33}$ in $200 \mu \mathrm{L}$ complete medium in 96-well plates. After 48 hours, cells were washed with FACS buffer and analyzed by flow cytometry. Data were analyzed using FlowJo software. 
Induction of acute GVHD. (B6xB10.A)F1 recipient mice $\left(\mathrm{H}-2^{\mathrm{a} / \mathrm{b}}\right)$ received 8-10 Gy total body irradiation and were maintained on drinking water containing antibiotics (sulfamethoxazole-trimethoprim, 0.25$0.75 \mathrm{mg} / \mathrm{mouse} /$ day). Eight hours after irradiation they received $10^{7} \mathrm{~T}$ cell-depleted BM cells from B6 WT and $5 \times 10^{6} \mathrm{LN}$ cells from B6 or $L c k^{559 \mathrm{~A}}$ mice by retro-orbital injection. BM cells were depleted of $\mathrm{T}$ cells by biotin anti-CD90.2 (Thy1.2) antibody and EasySep Streptavidin RapidSpheres according to the manufacturer's recommendations. Some BAF1 mice were given $10^{7} \mathrm{~B} 6 \mathrm{~T}$ cell-depleted $\mathrm{BM}$ cells after irradiation to be used as controls. CsA (20 mg/kg/mouse in PBS) was administered from the time of transfer (day 0) by i.p. injection. The recipients were monitored daily to assess survival and signs of aGVHD as adapted (26). The 5 following parameters were assessed, and scored 0 if absent or 1 if present: weight loss greater than $10 \%$ of initial weight, hunched posture, diarrhea, abnormal fur texture, and loss of skin integrity. Mice that received a score of 4 or whose weight loss exceeded $30 \%$ were euthanized. Mice that died received a score of 5 until the end of the experiment.

Preparation and analysis of infiltrating cells in the liver. Livers harvested from recipient mice were minced, passed through a $40 \mu \mathrm{m}$ mesh, and suspended in complete medium. Cells were washed once in complete medium. To remove erythrocytes, dead cells, and debris, the liver cell suspension was layered over Lympholyte-M and centrifuged for 20 minutes at $500 \mathrm{~g}$ at room temperature. The interface layer containing lymphocytes was transferred to new tubes and washed twice in compete medium. Cells were counted by trypan blue exclusion using light microscopy and a hemocytometer, and then analyzed by flow cytometry. The donor cell population was determined by the high level expression of $\mathrm{H}-2 \mathrm{~K}^{\mathrm{b}}$. After cell-surface staining, freshly isolated cells were fixed and permeabilized with BD Fixation/Permeabilization solution for 10 minutes at room temperature and then washed in Perm/Wash solution. These permeabilized cells were incubated overnight at $4^{\circ} \mathrm{C}$ with antibodies against perforin and granzyme B. Intracellular Foxp3 was detected using the Foxp3/Transcription Factor Staining Buffer Set. For intracellular cytokine staining, cells were stimulated PMA (phorbol 12-myristate 13-acetate, $10 \mathrm{ng} / \mathrm{mL})$ and ionomycin $(1 \mu \mathrm{g} / \mathrm{mL})$ in the presence of the GolgiStop protein transport inhibitor containing monensin (1/1000 dilution) for 3 hours at $37^{\circ} \mathrm{C}$ and then washed in FACS buffer. After cell-surface staining, intracellular IL-2 and IFN- $\gamma$ staining were performed as described above. Data were analyzed with FlowJo software.

Histopathology. Livers were harvested from recipients 30 days after transfer, cut into pieces, and placed in $10 \%$ formalin solution. The fixed liver pieces were embedded in paraffin and blocks of $4 \mu \mathrm{m}$ sections were stained with H\&E. A previously described scoring system (73) was used with minor modifications. In brief, 7 parameters were used to score aGVHD in the liver: bile duct epithelial changes, bile duct lymphocyte infiltration, endothelialitis, portal inflammation, lobular inflammation, apoptosis (0- to 3-point scale), and periductal lymphoid aggregates (0- to 2-point scale).

Generation of DCEK cells expressing $H-2 D^{b}$. A pcDNA3.1 vector containing full-length $H 2-D 1$ was provided by David H. Margulies (NIAID, Bethesda, Maryland USA). Fibroblastic DCEK cells that stably express I-E ${ }^{\mathrm{k}}$ and mouse ICAM1 (DCEK.ICAM.Hi7, a gift from Ron Germain, NIAID, Bethesda, Maryland USA) were maintained in complete medium and transfected with the DNA plasmid using Lipofectamine-2000 transfection reagent according to the manufacturer's protocol. Cells were selected in complete medium containing $400 \mu \mathrm{g} / \mathrm{mL}$ Zeocin for 2 weeks and then cell sorted for $\mathrm{H}-2 \mathrm{D}^{\mathrm{b}}$ positive cells (DCEK-D ${ }^{\mathrm{b}}$ ).
$T$ cell adhesion assay. For antigen-induced adhesion, monolayers of fibroblastic DCEK or DCEK-D ${ }^{\mathrm{b}}$ cells in 24-well plates were pulsed with medium or either MCC p $(1 \mu \mathrm{M})$ or gp33 $(1 \mu \mathrm{M})$ for 2 hours. Purified $\mathrm{T}$ cells from the lymph nodes of AND or P14 TCR-transgenic mice were added to the wells in complete medium with or without CsA $(100 \mathrm{ng} / \mathrm{mL})$, centrifuged at $500 \mathrm{~g}$ for 1 minute, and incubated for 30 minutes at $37^{\circ} \mathrm{C}$. Wells were washed 5 to 6 times with PBS and the adherent cells removed with $0.25 \%$ trypsin-EDTA and counted by trypan blue exclusion and light microscopy. For anti-TCR-induced adhesion, primary human $\mathrm{T}$ cells were stimulated with soluble antiCD3 (OKT3) and cross-linked with anti-mouse IgG, then incubated in 24-well plates coated with $2 \mu \mathrm{g} / \mathrm{mL}$ recombinant human ICAM1-Fc fragment at $37^{\circ} \mathrm{C}$. After 30 minutes, CsA was added and wells were washed 3 to 4 times with PBS 10 or 20 minutes later. Adherent cells were removed and counted as above.

Imaging by 2-photon microscopy. BMDCs were cultured with $5 \mu \mathrm{M}$ cognate peptide (MCC p or gp33) or control peptide (OVA-p) plus 1 $\mu \mathrm{g} / \mathrm{mL}$ LPS for 4 hours at $37^{\circ} \mathrm{C}$. After the incubation, BMDCs were washed by HBSS twice and labeled for 15 minutes at $37^{\circ} \mathrm{C}$ with 0.5 $\mu \mathrm{M}$ Deep Red dye. Labeled cells were washed once with complete medium and then resuspended in HBSS. BMDCs $\left(2.5 \times 10^{5}\right.$ cells $/ 20$ $\mu \mathrm{L}$ HBSS) were injected via footpad of recipient mice (B6 or BAF1) 16 to 18 hours before $\mathrm{T}$ cell injection. Purified AND or P14 T cells were labeled for 15 minutes at $37^{\circ} \mathrm{C}$ with $4 \mu \mathrm{M}$ CMFDA. Labeled T cells were washed as described above and resuspended in HBSS. Labeled T cells $\left(2 \times 10^{6}\right)$ were injected into recipient mice via retro-orbital sinus. Popliteal LNs (pLNs) were harvested at the indicated time. CsA (1 mg/mouse) was injected by 2 different ways depending on the experiment: (a) twice i.p. at the same time as DC and T cell injection, or (b) once i.v. 1 hour before harvesting LNs. To image deep into pLNs, tissue clearing was performed. Harvested LNs were quickly fixed with $4 \%$ paraformaldehyde for 30 minutes at room temperature and then rinsed 3 to 5 times with PBS. For lipid removal, pLNs were then incubated overnight in $1 \%$ Triton $\mathrm{X}-100$ at $4^{\circ} \mathrm{C}$. After rinsing with PBS, pLNs were cleared in FocusClear solution for more than 6 hours at $4^{\circ} \mathrm{C}$ and mounted on glass bottom dishes (MATSUNAMI) using MountClear solution. Images were acquired using an inverted laser-scanning 2-photon microscope (MPE-RS, Olympus) equipped with a tunable laser (Insight DS+, Spectra Physics). Images were acquired using a 252 water immersion objective NA 1.05 (XLPLN25XWMP2, Olympus). Excitation was performed at $810 \mathrm{~nm}$ and the emitted light was collected on 2 detectors (bandpass filters: green $=495-540 \mathrm{~nm}$ and $\mathrm{red}=575-645 \mathrm{~nm}$ ).

Analysis of imaging data. Images were analyzed using semiautomated analysis software (Imaris/Bitplane). For visualized $\mathrm{T}$ cells, spots were created with the built-in spot detection function in Imaris. The estimated T cell spot size was set to $7 \mu \mathrm{m}$. The Imaris surface function was used to create a digital surface corresponding to the surface of DCs. A T cell interaction with a DC was scored when the distance between the DC surface and $\mathrm{T}$ cell surface was less than or equal to $5 \mu \mathrm{m}$. Three dimensional distances were calculated using the Imaris Distance Transform MATLAB XTension. Clustering of T cells interacting with DCs were detected with the Split Spots function in the MATLAB XTension interfaced with Imaris. $T$ cell clusters were scored when there was a minimum of $3 \mathrm{~T}$ cells within $5 \mu \mathrm{m}$ of a DC and within $20 \mu \mathrm{m}$ of each other. The percentage of T/DC clusters was calculated as follow: (the number 
of DC interacting with more than $3 \mathrm{~T}$ cells/total number of DCs in imaged $\mathrm{pLNs}) \times 100 \%$. To visualize T/DC interactions, the images shown represent a $20 \mu \mathrm{m}$ thick virtual slice.

Statistics. All values are presented as mean \pm SEM or SD, as indicated. Statistical analysis was performed with GraphPad Prism 7 software. Statistical significance was determined with 1-way ANOVA with Tukey's multiple-comparison post hoc test unless otherwise indicated. $P$ less than 0.05 was considered to be statistically significant.

Study approval. Animal housing, care, and research were in accordance with the Guide for the Care and Use of Laboratory Animals (NIH publication no. 85-23; revised 1985), and all procedures on animals performed in this study were approved by the National Cancer Institute Animal Care and Use Committee.

\section{Author contributions}

SO and JDA conceived the project, designed experiments, analyzed data, and wrote the manuscript. SO and DD performed the experiments. NM and RW performed the 2-photon imaging experiments and supported analysis of the imaging data. MMG scored the pathology of liver aGVHD.

\section{Acknowledgments}

We thank R.E. Gress for critical reading of the manuscript and F. Livak for assistance with imaging flow cytometry. We also thank R.N. Germain (NIAID, Bethesda, Maryland USA) for the DCEK cells and D.H. Margulies (NIAID, Bethesda, Maryland USA) for the pcDNA3.1 vector containing full-length $H 2-D 1$. Traditional and imaging flow cytometry analyses were performed at the NCI LGI Flow Cytometry Core supported by funds from the Center for Cancer Research. This work was supported by the Intramural Research Program of the Center for Cancer Research, National Cancer Institute, NIH. MMG was supported by the German Research Foundation (GA 1818/2-3).

Address correspondence to: Jonathan D. Ashwell, Building 37, Room 3002, National Institutes of Health, Bethesda, Maryland 20892, USA.Email:jda@pop.nci.nih.gov.
1. Sayegh MH, Carpenter CB. Transplantation 50 years later - progress, challenges, and promises. N Engl JMed. 2004;351(26):2761-2766.

2. Burt RK, et al. Treatment of autoimmune disease by intense immunosuppressive conditioning and autologous hematopoietic stem cell transplantation. Blood.1998;92(10):3505-3514.

3. Bach JF. Immunosuppressive therapy of autoimmune diseases. Immunol Today. 1993;14(6):322-326.

4. Hartono C, et al. Immunosuppressive drug therapy. Cold Spring Harb Perspect Med. 2013;3(9):a015487.

5. Azzi JR, et al. Calcineurin inhibitors: 40 years later, can't live without. J Immunol. 2013;191(12):5785-5791.

6. Andersson, J et al. Effects of FK506 and cyclosporin A on cytokine production studied in vitro at a single-cell level. Immunology. 1992;75(1):136-142.

7. Flanagan, WM et al. Nuclear association of a T-cell transcription factor blocked by FK-506 and cyclosporin A. Nature. 1991;352(6338):803-807.

8. Liu J, et al. Calcineurin is a common target of cyclophilin-cyclosporin A and FKBP-FK506 complexes. Cell. 1991;66(4):807-815.

9. Rao A, et al. Transcription factors of the NFAT family: regulation and function. Annu Rev Immunol. 1997;15:707-747.

10. Liu J, et al. Inhibition of T cell signaling by immunophilin-ligand complexes correlates with loss of calcineurin phosphatase activity. Biochemistry. 1992;31(16):3896-3901.

11. Lee JU, et al. Revisiting the concept of targeting NFAT to control T cell immunity and autoimmune diseases. Front Immunol. 2018;9:2747.

12. Dutta D, et al. Recruitment of calcineurin to the TCR positively regulates $\mathrm{T}$ cell activation. $\mathrm{Nat}$ Immunol. 2017;18(2):196-204.

13. Watts JD, et al. Phosphorylation of serine 59 of p56lck in activated T cells. J Biol Chem. 1993;268(31):23275-23282.

14. Paster W, et al. A THEMIS:SHP1 complex promotes T-cell survival. EMBO J. 2015;34(3):393-409.

15. Macian F. NFAT proteins: key regulators of T-cell development and function. Nat Rev Immunol.
2005;5(6):472-484

16. Macián F, et al. Partners in transcription: NFAT and AP-1. Oncogene. 2001;20(19):2476-2489.

17. Hodge MR, et al. Hyperproliferation and dysregulation of IL-4 expression in NF-ATp-deficient mice. Immunity. 1996;4(4):397-405.

18. Kim HP, Leonard WJ. The basis for TCR-mediated regulation of the IL-2 receptor alpha chain gene: role of widely separated regulatory elements. EMBO J. 2002;21(12):3051-3059.

19. Aramburu J, et al. Affinity-driven peptide selection of an NFAT inhibitor more selective than cyclosporin A. Science. 1999;285(5436):2129-2133.

20. Chow CW, et al. Requirement for transcription factor NFAT in interleukin-2 expression. Mol Cell Biol. 1999;19(3):2300-2307.

21. Sica A, et al. Interaction of NF-kappaB and NFAT with the interferon-gamma promoter. J Biol Chem. 1997;272(48):30412-30420.

22. Kiani A, et al. Down-regulation of IL-4 gene transcription and control of Th2 cell differentiation by a mechanism involving NFAT1. Immunity. 1997;7(6):849-860.

23. Malard F, et al. Impact of cyclosporine-A concentration on the incidence of severe acute graftversus-host disease after allogeneic stem cell transplantation. Biol Blood Marrow Transplant. 2010;16(1):28-34.

24. Storb R, et al. Methotrexate and cyclosporine compared with cyclosporine alone for prophylaxis of acute graft versus host disease after marrow transplantation for leukemia. $\mathrm{N} \mathrm{Engl} \mathrm{JMed}$. 1986;314(12):729-735.

25. Yee GC, et al. Serum cyclosporine concentration and risk of acute graft-versus-host disease after allogeneic marrow transplantation. $N$ Engl J Med. 1988;319(2):65-70.

26. Naserian S, et al. Simple, reproducible, and efficient clinical grading system for murine models of acute graft-versus-host disease. Front Immunol. 2018;9:10.

27. Ju JM, et al. Kinetics of IFN- $\gamma$ and IL-17 production by CD 4 and CD 8 T cells during acute graft-versus-host disease. Immune Netw. 2014;14(2):89-99.
28. Zhao K, et al. Dynamic regulation of effector IFN- $\gamma$-producing and IL-17-producing T cell subsets in the development of acute graft-versushost disease. Mol Med Rep. 2016;13(2):1395-1403.

29. Wu T, et al. Immunosuppressive drugs on inducing Ag-specific CD4(+)CD25(+)Foxp3(+) Treg cells during immune response in vivo. Transpl Immunol. 2012;27(1):30-38.

30. Fontenot JD, et al. A function for interleukin 2 in Foxp3-expressing regulatory T cells. Nat Immunol. 2005;6(11):1142-1151.

31. Tone $Y$, et al. Smad3 and NFAT cooperate to induce Foxp3 expression through its enhancer. Nat Immunol. 2008;9(2):194-202.

32. Du W, Cao X. Cytotoxic pathways in allogeneic hematopoietic cell transplantation. Front Immunol. 2018;9:2979.

33. Trapani JA, Smyth MJ. Functional significance of the perforin/granzyme cell death pathway. Nat Rev Immunol. 2002;2(10):735-747.

34. van den Brink MR, Burakoff SJ. Cytolytic pathways in haematopoietic stem-cell transplantation. Nat Rev immunol. 2002;2(4):273-281.

35. Latinis KM, et al. Regulation of CD95 (Fas) ligand expression by TCR-mediated signaling events. Jimmunol. 1997;158(10):4602-4611.

36. Holtz-Heppelmann CJ, et al. Transcriptional regulation of the human FasL promoter-enhancer region. J Biol Chem. 1998;273(8):4416-4423.

37. Liu CC, et al. Perforin and serine esterase gene expression in stimulated human T cells. Kinetics, mitogen requirements, and effects of cyclosporin A. JExp Med.1989;170(6):2105-2118.

38. Lu P, et al. Perforin expression in human peripheral blood mononuclear cells. Definition of an IL-2-independent pathway of perforin induction in CD8+ T cells. JImmunol. 1992;148(11):3354-3360.

39. Mueller C, et al. The effect of cyclosporine treatment on the expression of genes encoding granzyme $\mathrm{A}$ and perforin in the infiltrate of mouse heart transplants. Transplantation. 1993;55(1):139-145.

40. Voskoboinik I, et al. Perforin and granzymes: function, dysfunction and human pathology. Nat Rev Immunol. 2015;15(6):388-400. 
41. Walling BL, Kim M. LFA-1 in T cell migration and differentiation. Front Immunol. 2018;9:952.

42. Nurmi SM, et al. Phosphorylation of the LFA-1 integrin beta2-chain on Thr-758 leads to adhesion, Rac-1/Cdc42 activation, and stimulation of CD69 expression in human T cells. J Biol Chem. 2007;282(2):968-975.

43. Clipstone NA, Crabtree GR. Identification of calcineurin as a key signalling enzyme in T-lymphocyte activation. Nature. 1992;357(6380):695-697.

44. Jain J, et al. The T-cell transcription factor NFATp is a substrate for calcineurin and interacts with Fos and Jun. Nature. 1993;365(6444):352-355.

45. Brunton LL, et al. Immunosuppressants and tolerogens. In: Brunton LL, et al, eds. Goodman and Gilman's The Pharmacological Basis of Therapeutics, 13th Edition. McGraw Hill; 2017:1808.

46. Shlomchik WD. Graft-versus-host disease. Nat Rev Immunol. 2007;7(5):340-352.

47. Varga G, et al. LFA-1 contributes to signal I of T-cell activation and to the production of $\mathrm{T}(\mathrm{h}) 1$ cytokines. JInvest Dermatol. 2010;130(4):1005-1012.

48. Wang Y, et al. LFA-1 affinity regulation is necessary for the activation and proliferation of naive T cells. J Biol Chem. 2009;284(19):12645-12653.

49. Harning R, et al. Reduction in the severity of graft-versus-host disease and increased survival in allogenic mice by treatment with monoclonal antibodies to cell adhesion antigens LFA- 1 alpha and MALA-2. Transplantation. 1991;52(5):842-845.

50. Howell CD, et al. Role of intercellular adhesion molecule- 1 and lymphocyte function-associated antigen-1 during nonsuppurative destructive cholangitis in a mouse graft-versus-host disease model. Hepatology. 1999;29(3):766-776.

51. Wang $Y$, et al. LFA-1 decreases the antigen dose for $\mathrm{T}$ cell activation in vivo. Int Immunol. 2008;20(9):1119-1127.
52. Dugger KJ, et al. Effector and suppressor roles for LFA-1 during the development of experimental autoimmune encephalomyelitis. J Neuroimmunol. 2009;206(1-2):22-27.

53. Wang Y, et al. Blocking LFA-1 activation with lovastatin prevents graft-versus-host disease in mouse bone marrow transplantation. Biol Blood Marrow Transplant. 2009;15(12):1513-1522.

54. Liang $Y$, et al. Beta 2 integrins separate graftversus-host disease and graft-versus-leukemia effects. Blood. 2008;111(2):954-962.

55. Bolitho P, et al. Apoptosis induced by the lymphocyte effector molecule perforin. Curr Opin Immunol. 2007;19(3):339-347.

56. Kägi D, et al. Cytotoxicity mediated by $\mathrm{T}$ cells and natural killer cells is greatly impaired in perforin-deficient mice. Nature. 1994;369(6475):31-37.

57. Pipkin ME, et al. The transcriptional control of the perforin locus. Immunol Rev. 2010;235(1):55-72.

58. Klein-Hessling S, et al. NFATc1 controls the cytotoxicity of $\mathrm{CD} 8^{+} \mathrm{T}$ cells. Nat Commun . 2017;8(1):511.

59. Shan $\mathrm{Q}$, et al. The transcription factor Runx3 guards cytotoxic $\mathrm{CD} 8^{+}$effector $\mathrm{T}$ cells against deviation towards follicular helper $\mathrm{T}$ cell lineage. Nat Immunol. 2017;18(8):931-939.

60. Cruz-Guilloty F, et al. Runx3 and T-box proteins cooperate to establish the transcriptional program of effector CTLs. JExp Med. 2009;206(1):51-59.

61. Noguchi H, et al. A new cell-permeable peptide allows successful allogeneic islet transplantation in mice. Nat Med. 2004;10(3):305-309.

62. Choi JM, et al. Cell permeable NFAT inhibitory peptide Sim-2-VIVIT inhibits T-cell activation and alleviates allergic airway inflammation and hyper-responsiveness. Immunol Lett. 2012;143(2):170-176.

63. Lee HG, et al. NFAT-specific inhibition by
dNP2-VIVITAmeliorates autoimmune encephalomyelitisby regulation of Th1 and Th17. Mol Ther Methods Clin Dev. 2020;16:32-41.

64. Baker MB, et al. The role of cell-mediated cytotoxicity in acute GVHD after MHC-matched allogeneic bone marrow transplantation in mice. JExp Med.1996;183(6):2645-2656.

65. Braun MY, et al. Cytotoxic T cells deficient in both functional fas ligand and perforin show residual cytolytic activity yet lose their capacity to induce lethal acute graft-versus-host disease. JExp Med.1996;183(2):657-661.

66. Graubert TA, et al. Perforin/granzyme-dependent and independent mechanisms are both important for the development of graft-versushost disease after murine bone marrow transplantation. JClin Invest. 1997;100(4):904-911.

67. Jiang $\mathrm{H}$, et al. Role of $\mathrm{CD} 8+\mathrm{T}$ cells in murine experimental allergic encephalomyelitis. Science. 1992;256(5060):1213-1215.

68. Robinson DS. The role of the $\mathrm{T}$ cell in asthma. J Allergy Clin Immunol. 2010;126(6):1081-1091.

69. Guy CS, et al. Distinct TCR signaling pathways drive proliferation and cytokine production in $\mathrm{T}$ cells. Nat Immunol. 2013;14(3):262-270.

70. Sade H, et al. The anti-apoptotic effect of Notch-1 requires p56lck-dependent, Akt/ PKB-mediated signaling in T cells. J Biol Chem. 2004;279(4):2937-2944.

71. Bechstein WO. Neurotoxicity of calcineurin inhibitors: impact and clinical management. Transpl Int. 2000;13(5):313-326.

72. Textor SC, et al. Posttransplantation hypertension related to calcineurin inhibitors. Liver Transpl. 2000;6(5):521-530.

73. Quaglia A, et al. Histopathology of graft versus host disease of the liver. Histopathology. 2007;50(6):727-738. 